\title{
Poly(ADP-ribose): PARadigms and PARadoxes
}

\author{
Alexander Bürkle ${ }^{\mathrm{a}, *}$, László Virág ${ }^{\mathrm{b}, \mathrm{c}, *}$ \\ ${ }^{a}$ Department of Biology, University of Konstanz, Konstanz, Germany \\ ${ }^{\mathrm{b}}$ Department of Medical Chemistry, Medical and Health Science Center, University of Debrecen, Debrecen, Hungary \\ ${ }^{\mathrm{c}}$ MTA DE Cell Biology and Signaling Research Group, Debrecen, Hungary
}

Keywords:

Poly(ADP-ribose) polymerase

Poly(ADP-ribose) glycohydrolase

Cell death

Necrosis

Apoptosis

DNA repair

Transcription

Chromatin structure

Mitochondria

Calcium

Signaling

Kinase

\begin{abstract}
A B S T R A T
Poly(ADP ribosyl)ation (PARylation) is a posttranslational protein modification (PTM) cat alyzed by members of the poly(ADP ribose) polymerase (PARP) enzyme family. PARPs use $\mathrm{NAD}^{+}$as substrate and upon cleaving off nicotinamide they transfer the ADP ribosyl moiety covalently to suitable acceptor proteins and elongate the chain by adding further ADP ribose units to create a branched polymer, termed poly(ADP ribose) (PAR), which is rapidly degraded by poly(ADP ribose) glycohydrolase (PARG) and ADP ribosylhydrolase 3 (ARH3). In recent years several key discoveries changed the way we look at the biological roles and mode of operation of PARylation. These paradigm shifts include but are not limited to (1) a single PARP enzyme expanding to a PARP family; (2) DNA break dependent activation extended to several other DNA dependent and independent PARP activation mechanisms; (3) one molecular mechanism (covalent PARylation of target proteins) underlying the bio logical effect of PARPs is now complemented by several other mechanisms such as protein protein interactions, PAR signaling, modulation of $\mathrm{NAD}^{+}$pools and (4) one principal biolog ical role in DNA damage sensing expanded to numerous, diverse biological functions iden tifying PARP 1 as a real moonlighting protein. Here we review the most important paradigm shifts in PARylation research and also highlight some of the many controversial issues (or paradoxes) of the field such as (1) the mostly synergistic and not antagonistic biological effects of PARP 1 and PARG; (2) mitochondrial PARylation and PAR decomposi tion, (3) the cross talk between PARylation and signaling pathways (protein kinases, phos phatases, calcium) and the (4) divergent roles of PARP/PARylation in longevity and in age related diseases.
\end{abstract}

\section{Contents}

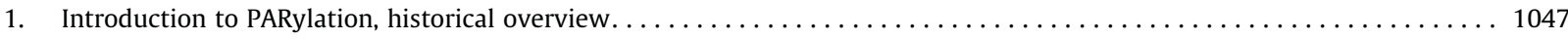

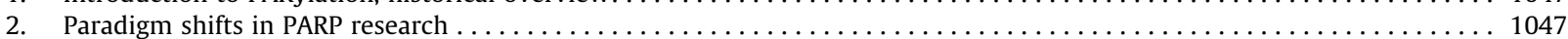

2.1. Old paradigm \#1: there is one PARP enzyme. New paradigm: PARP 1 is one of the many members of the PARP

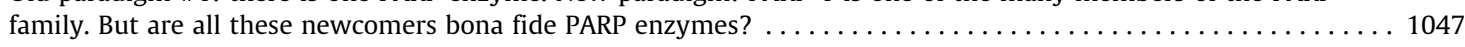

2.2. Old paradigm \#2: DNA breaks activate PARP. New paradigm: special DNA structures and PTM can also activate

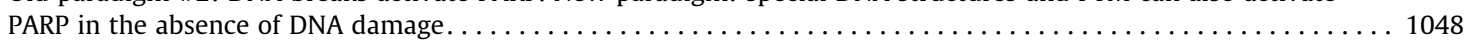

2.3. Old paradigm \#3: PARP acts by covalently modifying target proteins and changing their physicochemical properties. New paradigm: Complex mechanisms such as protein protein interactions, free PAR signaling, or changes in $\mathrm{NAD}^{+}$levels underlie the biological roles of PARPs

\footnotetext{
* Corresponding authors. Address: Department of Biology, University of Konstanz, D-78457 Konstanz, Germany. Tel.: +49 7531884034 ; fax: +49 7531 88 4033 (A. Bürkle), Department of Medical Chemistry, Medical and Health Science Center, University of Debrecen, Nagyerdeikrt 98 , H-4032 Debrecen, Hungary. Tel.: +36 52412 345; fax: +36 52412566 (L. Virág)

E-mail addresses: alexander.buerkle@uni-konstanz.de (A. Bürkle), lvirag@med.unideb.hu (L. Virág).
} 
2.4. Old paradigm \#4: PARylation is a DNA repair aiding mechanism. New paradigm: PARylation is a versatile PTM

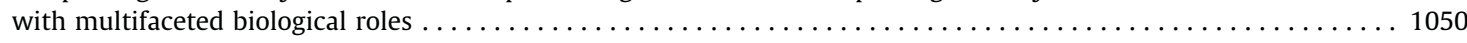

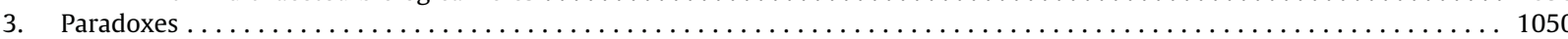

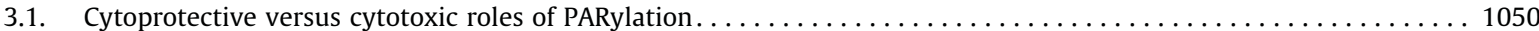

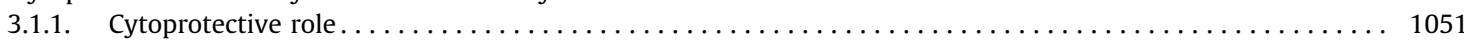

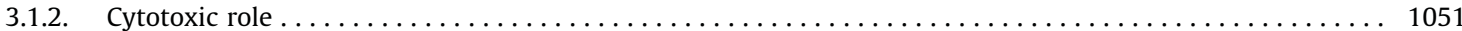

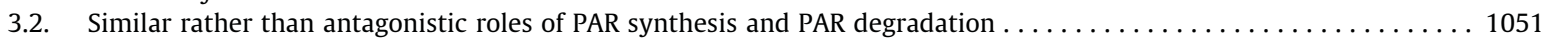

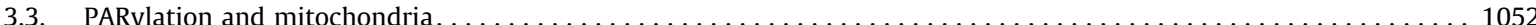

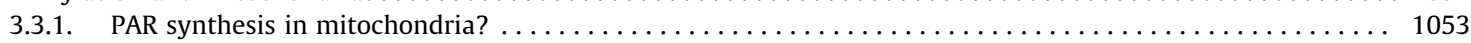

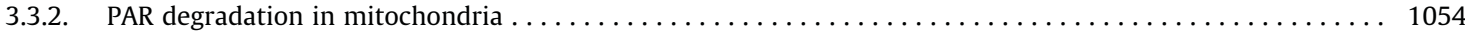

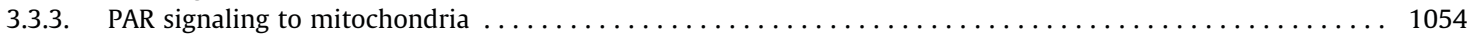

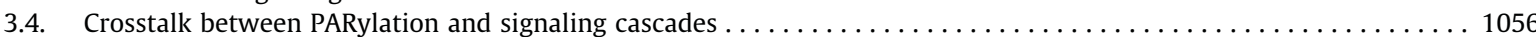

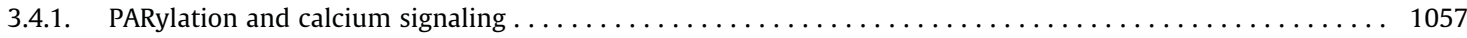

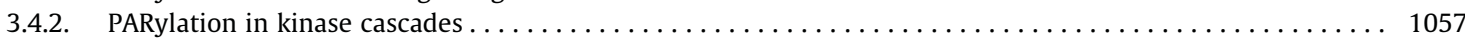

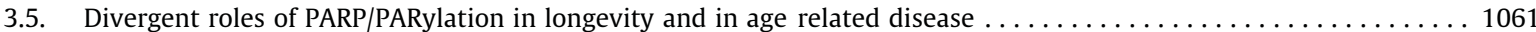

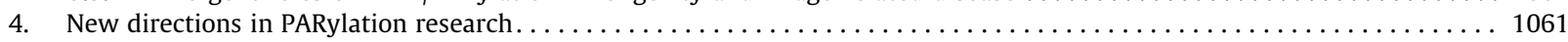

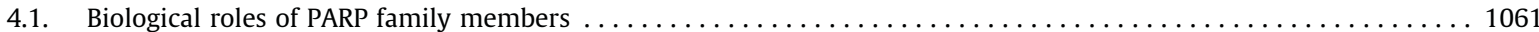

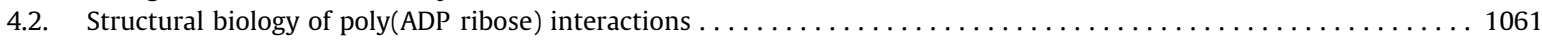

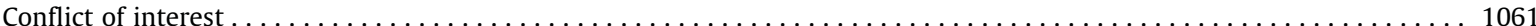

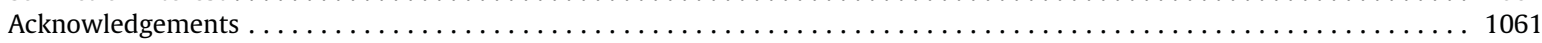

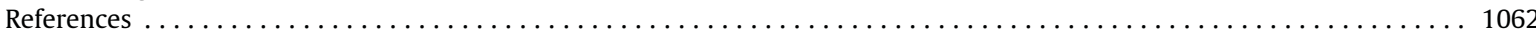

\section{Introduction to PARylation, historical overview}

In the 1960s, three research groups pioneered the discovery of a novel nucleic acid like macromolecule, poly(ADP ribose) [PAR], whose formation turned out to depend on NAD (Chambon et al., 1963; Nishizuka et al., 1967; Sugimura et al., 1967). The first group, headed by Paul Mandel, initially had assumed the homopolymeric reaction product to be poly A but soon there was agreement in the newly founded field that the product is indeed PAR. Over the last 50 years this fascinating mol ecule has aroused the interest of a large number of scientists world wide, coming from a very broad range of fields of sci entific research.

The first phase of PAR research featured mostly biochemical work leading to the purification of the proteins responsible for its synthesis, i.e. poly(ADP ribose) polymerase [PARP; later termed PARP 1 or ARTD1], and poly(ADP ribose) glycohydro lase [PARG] (Bürkle, 2006; de Murcia and Shall, 2000). Another important biochemical topic was the identification of the tar get amino acids for covalent modification of proteins with PAR, i.e. glutamate, aspartate and lysine and the establishment of a quantitative assay to determine PAR levels in living cells (Juarez Salinas et al., 1979).

In a second phase, cell biologist and pharmaco toxicologists started to become interested in the subject matter, based on the availability of cell permeable, first generation PARP inhibitors like nicotinamide, benzamide or 3 aminobenzamide. Using such compounds, sensitization of cultured cells to the cytotoxic effects of low doses of alkylating agents was observed (Durkacz et al., 1980). This led, early on, to the idea of combining DNA damaging cytotoxic agents used in cancer chemother apy with PARP inhibitors in order to enhance the cytotoxic effect especially in poorly responsive cancer types.

A third phase of PAR research was triggered by the advent of molecular biology. Three groups pioneered the molecular cloning of PARP 1 cDNA (Cherney et al., 1987; Kurosaki et al., 1987; Suzuki et al., 1987), which brought an enormous stim ulus to the field in a variety of ways.

A fourth phase may be viewed in the use of methodology of structural biology to tackle PARylation. This included the crystal structure of PARP 1 (Langelier et al., 2012; Ruf et al., 1996, 1998) followed by a more comprehensive coverage of the additional members of the PARP family (Karlberg et al., 2010) and the discovery of a histone macrodomain as a PAR bind ing motif (Timinszky et al., 2009), see Section 2.2).

Our review is built around important paradigm shifts/milestones of the field and also highlights controversial issues ("paradoxes").

\section{Paradigm shifts in PARP research}

2.1. Old paradigm \#1: there is one PARP enzyme. New paradigm: PARP 1 is one of the many members of the PARP family. But are all these newcomers bona fide PARP enzymes?

Purification of the major enzymatic activity that produced PAR yielded a $\sim 116 \mathrm{kD}$ protein, which was termed ADP ribo syltransferase (ADPRT) or poly(ADP ribose) synthetase (PARS) or poly(ADP ribose) polymerase (PARP) [EC 2.4.2.30]. This nu clear protein is highly conserved and constitutively expressed. It is catalytically active as a dimer and is the major acceptor protein in intact cells, via automodification. It displays a characteristic three domain structure, which can be further broken 
down into 8 modules (Hottiger et al., 2010). The $\mathrm{N}$ terminal 42 kDa DNA binding domain (DBD) of this enzyme binds to sin gle or double strand breaks with high affinity via two zinc fingers, which leads to an immediate, massive stimulation of enzyme activity. In the absence of DNA breaks, PARP displays a very low basal enzyme activity. This is the reason for the massive formation of PAR by living cells immediately upon exposure to DNA damaging agents such as ionizing radiation, alkylating agents and oxidants.

Molecular cloning led to the chromosomal mapping of the respective gene to human chromosome 1q41 q42. Parp 1 knockout mice were independently established by three different groups and proved viable and fertile but did show a num ber of phenotypes. Surprisingly, cells from such mice did display residual PAR formation upon genotoxic treatment (Shieh et al., 1998). This was the basis for the search of additional proteins capable of catalyzing the formation of PAR. Meanwhile this search has led to a total of six human genes encoding proteins with proven capability to produce PAR (PARPs 1, 2, and 3, vPARP, tankyrases 1 and 2) plus another 12 genes that share the "PARP signature" sequence, yet appear to transfer only a single ADP ribosyl residue onto target proteins. Recently a new, unifying nomenclature (ARTD1 through 18) was proposed for the members of this gene family (Hottiger et al., 2010). It may well be that this set of 18 human genes encode an even larger number of polypeptides as a result of alternative promoter usage or splicing.

\subsection{Old paradigm \#2: DNA breaks activate PARP.}

New paradigm: special DNA structures and PTM can also activate PARP in the absence of DNA damage

The "central dogma" of PARylation states that PARP 1 is activated by DNA damage. Indeed, reactive oxygen and nitrogen species (ROS and RNS, respectively) and DNA alkylating agents have been used extensively to trigger PAR synthesis in various cellular models. Whereas ROS and RNS can break DNA strands directly, alkylating agents such as MNNG and MNU methylate DNA bases, the repair of which involves glycosylases that remove altered bases leaving behind apurinic sites triggering the activation of APE (apurinic endonuclease) that creates a PARP activating nick in the DNA.

An interesting twist in this story of DNA break inducible PARP activation was the discovery that DNA breaks generated by topoisomerase II $\beta$ may also serve as activator of PARP 1 and serve as underlying mechanism for the transcription regulatory role of PARylation e.g. in nuclear receptor mediated transcription (Ju et al., 2006). In this paper Ju et al. demonstrated that in MCF7 cells, $17 \beta$ estradiol treatment lead to depletion of proteins of the PARP 1 co repressor complex (HSP70, nucleolin, nucleophosmin) from and recruitment of PARP 1 (along with topoismerase II $\beta$ and members of DNA double strand break repair such as DNA PK, Ku86 and Ku70) to the promoter of the estrogen inducible protein pS2. Moreover, topoisomerase II $\beta$ mediated DNA double strand breaks were surprisingly identified as the trigger for PARP activation in this model which appears to be a rather general mechanism as it has also been confirmed to be relevant in androgen receptor, retinoic acid receptor, thyroid receptor and activating protein 1 dependent transcriptional activation (Ju et al., 2006).

Several lines of evidence indicate that PARP 1 may also be activated in the absence of DNA breakage. For example special non B DNA structures such as bent, cruciform DNA or stably unpaired DNA regions have been described as stimulators of PARP activity (Lonskaya et al., 2005). Another mode of "alternative" PARP activation is based on signaling mechanisms with special regard to kinase cascades. PARP 1 interacts with various signaling pathways (discussed in detail under Section 3.4). Although the nature of these interactions is complex, it often involves a kinase phosphorylating PARP 1, which leads to its activation. Variations to this theme include (1) direct protein protein interaction between PARP 1 and a pre phosphorylated kinase (e.g. phospho Erk) where this direct interaction and not phosphorylation of PARP 1 mediates PARP activation (Cohen Armon, 2007; Cohen Armon et al., 2007) and (2) kinase mediated inhibition of PARP 1 (e.g. in the case of PKC) (Bauer et al., 1992; Hegedus et al., 2008; Tanaka et al., 1987). These "alternative" PARP activation mechanisms have been implicated in transcriptional regulation and cell death.

DNA damage and PTM may also synergistically activate PARP 1. Mao et al. (2011) have shown that the role of SIRT6 in double strand break repair requires interaction between SIRT6 and PARP 1 . SIRT6 was shown to activate PARP 1 by mono ADP ribosylating it in position Lys521 whereas the deacetylation activity of SIRT6 was dispensable for PARP activa tion. The multilevel cross talk between Sirtuins and PARP 1 are discussed in detail in (Canto et al., 2013). Mono ADP ribo sylation of PARP 1 may not be an isolated activation mechanism as PARP 3 has also been shown to activate PARP 1 by mono ADP ribosylation in the absence of DNA (Loseva et al., 2010).

Not only the activity but also protein protein interactions of PARP 1 may be regulated by PTMs. Hassa et al. (Haenni et al., 2008; Hassa et al., 2005) have shown for example that acetylation of PARP 1 by p300/CBP was required for the NF $\kappa B$ co activator function of PARP 1 . This effect has previously been proven to be independent of the DNA binding and enzymatic functions of PARP 1 (Hassa et al., 2001). Later PARP 2 also joined the cast of PARPs undergoing acetylation as Haenni et al. (2008) demonstrated that it is a substrate for the histone acetyltransferases PCAF and GCN5L, and acetylation resulted in reduced DNA binding and consequently decreased activity of PARP 2.

2.3. Old paradigm \#3: PARP acts by covalently modifying target proteins and changing their physicochemical properties. New paradigm: Complex mechanisms such as protein protein interactions, free PAR signaling, or changes in NAD ${ }^{+}$levels underlie the biological roles of PARPs

Soon after the discovery of PAR (Chambon et al., 1963; Nishizuka et al., 1967; Sugimura et al., 1967) it was recognized that PARylation is a posttranslational modification of proteins (Nishizuka et al., 1968) and a conspicuous number of covalently 
modified target proteins (acceptor proteins) have been identified. It was therefore obvious to assume that covalent PARyla tion of a given acceptor protein primarily should affect the physicochemical properties of this protein, similar to the effects of many other posttranslational modifications, such as phosphorylation. It was intriguing, however, to note that the most abun dant acceptor protein for PARylation found under conditions of DNA damage was PARP 1 itself, via "automodification". An other important observation was the non covalent binding of selected proteins to free ADP ribose chains (Panzeter et al., 1992; Sauermann and Wesierska Gadek, 1986). Later on, the first PAR binding motif was identified, which comprised several hydrophobic and basic amino acids in a distinct order and with distinct spacing (Pleschke et al., 2000). In more recent work the binding affinity of PAR of defined chain length could be determined and the results indicated an overall higher binding affinity for longer chains, but also a strong dependence of binding affinity on the specific binding protein studied. Maximal binding affinity proved to be very high, with $K_{\mathrm{D}}$ values in the low nanomolar range. (Fahrer et al., 2007; Fahrer et al., 2010; Kappes et al., 2008; Popp et al., in press). In recent years, two additional PAR binding motifs were discovered, i.e. a PAR bind ing zinc finger motif (Ahel et al., 2008) and a histone macrodomain (Timinszky et al., 2009). Viewed together, PARylation emerges as a generic cellular mechanism for informing a large number of specific proteins via non covalent interaction, lead ing to the recruitment of the protein to a specific site (e.g. the site of a DNA strand break sensed by PARP 1) or changes in its functional status. In view of the rapid turnover of PAR in living cells, this mechanism appears highly versatile, as it can be switched on or off very rapidly.

But apart from being covalently attached to PARPs, free PAR can also serve as an important intracellular signaling mol ecule. This has been exemplified by the discovery of cell death induced by free PAR triggering the release of apoptosis induc ing factor from mitochondria (see Section 3.1) (Andrabi et al., 2006; Wang et al., 2011; Yu et al., 2002, 2006). It should be noted that under certain circumstances (e.g. massive DNA damage), a cellular consequence of PARP activity is not only the formation of PAR, but also a significant consumption of its substrate, NAD ${ }^{+}$. It was originally proposed by Berger et al. that under extreme conditions the depletion of cellular NAD ${ }^{+}$may even lead to cells death (Berger et al., 1983) and subse quent work by many groups has shown that PARP inhibitors or PARP 1 gene knockout or knockdown indeed can prevent

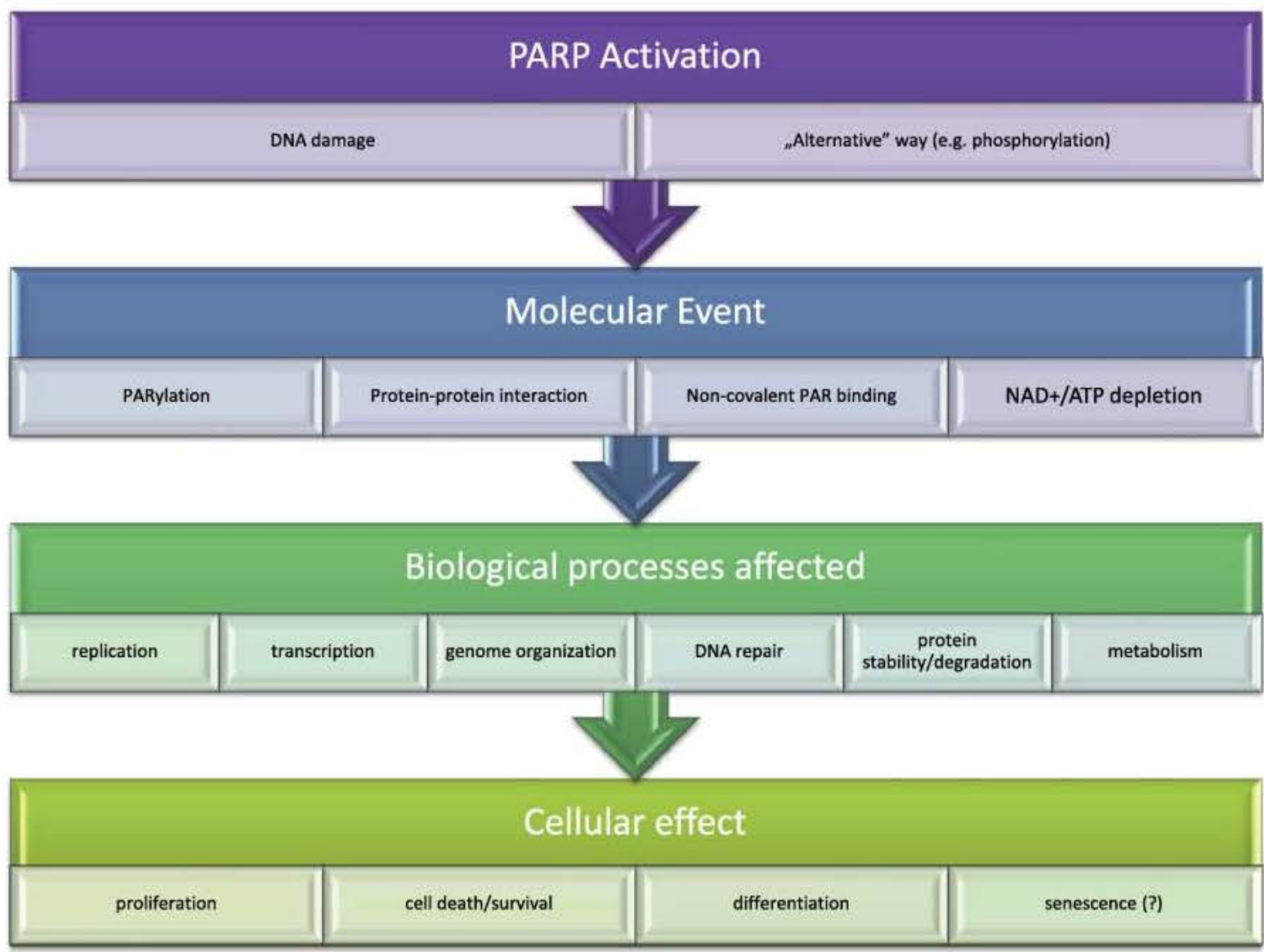

Fig. 1. "Layers" of PARylation. PARPs can be activated by DNA breaks or by alternative mechanisms such as phosphorylation. At the molecular level, downstream events of PARP signaling involve either covalent PARylation of substrates, protein-protein interaction between PARPs and partner proteins, non-covalent binding of PAR polymer to proteins bearing a PAR-binding motif and lowering of cellular NAD ${ }^{+}$/ATP levels. Via these pathways PARP/ PARylation regulates various machineries such as replication, transcription, DNA repair, metabolism mediating various cellular phenomena such as proliferation, differentiation, senescence and cell death. 
$\mathrm{NAD}^{+}$depletion and acute cell death ((Virág and Szabo, 2002) and Virág et al., 2013). Such a scenario was recently under pinned by the fact that supplementation with the $\mathrm{NAD}^{+}$precursor nicotinic acid prevented necrotic cell death in human peripheral blood mononuclear cells exposed to DNA damaging agents, while cellular PAR formation was boosted (Weidele et al., 2010). Severe PARP dependent NAD ${ }^{+}$depletion was also recorded in Nijmegen Breakage Syndrome cells, which are characterized by defects in the sensing and repair of DNA double strand breaks (Krenzlin et al., 2012). It should be kept in mind, however, that even under sublethal conditions, PARP dependent lowering of NAD levels may play an important biological role by interfering with enzymatic activity of sirtuins (see Section 2.2). The different layers of PARylation including its activation mechanisms, effects at the molecular and cellular level are summarized on Fig. 1.

\subsection{Old paradigm \#4: PARylation is a DNA repair aiding mechanism.}

New paradigm: PARylation is a versatile PTM with multifaceted biological roles

PARylation started its "career" as a DNA damage responsive protein modification reaction that is required for the efficient repair of DNA breaks. By now a substantial amount of data has accumulated to change our view on the biological function(s) of PARylation. On the one hand the high abundance of the PARP 1 protein in the nucleus permits its immediate response to DNA damage while on the other hand it also calls out for "alternative" functions in order for the cells to economically utilize this valuable resource even in the absence of DNA damage. As we have learned more and more about these "alternative" functions, they often turned out to be as fundamental as the role of PARylation in DNA repair.

For example, PARP 1 is now recognized as an integral part of the chromatin. Kraus's group has elegantly demonstrated in Drosophila polytene chromosomes (Kim et al., 2004) that PARP 1 and H1 localize to distinct and non overlapping chromatin regions. They also observed that PARP 1 localized to the less compact regions whereas $\mathrm{H} 1$ was present in the compact chro matin areas. The same group has later demonstrated a reciprocal binding of PARP 1 and histone H1 at promoters in a mam malian cell genome and showed that PARP 1 was enriched and $\mathrm{H} 1$ was depleted at RNA polymerase II transcribed promoters (Krishnakumar et al., 2008). Moreover, this study provided evidence that PARP 1 actively excluded H1 from chromatin and further confirmed the role of PARylation in transcription coupled regulation of chromatin structure.

The complex role of PARylation in the regulation of transcription goes beyond its contribution to chromatin remodeling. PARP 1 has been shown to regulate the effect of a large number of transcription factors. The molecular mechanism of these effects is largely unknown but for some transcription factors it has been characterized in more detail (Kraus and Hottiger, 2013). In the case of NFKB, a protein protein interaction between PARP 1 and the transcription factor appears to underlie the NFKB co activator function of PARP 1. Interestingly this effect did not require the DNA binding or the enzyme activity of PARP 1 (Hassa et al., 2001). Recently data from a genome wide mapping also pointed out that on some promoters the reg ulatory role of PARP did whereas on others it did not require enzyme activity (Frizzell et al., 2009).

The regulatory roles of PARP 1 and PARylation, however, are not limited to chromatin organization and transcription (see also Kraus and Hottiger, 2013), although these should also be regarded as fundamental roles. Replication, telomere mainte nance, metabolism, cell fates should also be added to the continuously growing "to do list" of PARP 1/PARylation as covered in the reviews following this introductory paper.

In the light of the plethora of diverse biological functions now assigned to PARylation we should revise our view on what we consider a "fundamental" or "primary" role of PARylation and what we consider an "accessory" or "secondary" role. It seems that PARP 1 is a prototypical moonlighting protein that has acquired multiple cellular functions during evolution. Ful filling these multiple tasks is made possible by its enzyme activities, protein protein interactions with partner proteins and posttranslational modifications (e.g. phosphorylation, acetylation, ADP ribosylation). Considering multifunctionality of en zymes as a norm rather than an exception from the rule (Jeffery, 2003) may relieve the pain one feels when trying to prior itize protein functions and may help us accept it as one of the miracles of evolution.

\section{Paradoxes}

Several aspects of PARylation are highly controversial and the often opposing biological functions assigned to it are dif ficult to reconcile. Here we highlight four such areas:

(A) How is it possible that PARylation as a cell survival mechanism can also mediate cell death?

(B) While PARP 1 and PARG represent opposite arms (synthesis and degradation) of the PARylation cycle, they often show similar and only rarely divergent biological effects.

(C) While PARP appears to be in the center of a bidirectional nuclear mitochondrial crosstalk, there is a considerable con troversy regarding the existence and identity of mitochondrial PAR synthesizing and degrading activities.

(D) Divergent roles of PARP/PARylation in longevity and in age related diseases.

\subsection{Cytoprotective versus cytotoxic roles of PARylation}

One of the most intriguing and controversial issue in PARylation research is the complex role of PARP enzymes and PARy lation in cell death regulation. On the one hand PARylation is known as a survival enhancing mechanism assisting the recov 
ery of cells from DNA damage induced injury. On the other hand excessive PARylation cycles or certain PAR dependent path ways may signal cell death in a complex, cell type and stimulus dependent manner.

\subsubsection{Cytoprotective role}

PARP 1, 2 and 3 are DNA damage sensitive members of the PARP family. Whereas the role of PARP 1 (and recently also that of PARP 2) in DNA damage signaling has been extensively documented (De Vos et al., 2012) (see Robert et al., 2013), the role of PARP 3 is less well characterized. PARP 1 and 2 are activated by DNA strand breaks caused e.g. by reactive oxygen or nitrogen species (ROS and RNS, respectively) or by base excision repair (BER) mechanisms introducing breaks into DNA at sites of alkylation. The ADP ribose polymer synthesized by PARPs in response to DNA injury serves as a "flag" marking the sites of DNA damage and assisting the recruitment of further DNA repair adaptor and effector proteins (De Vos et al., 2012). Efficient DNA repair is required for the survival of injured cells and thus inhibition of PARylation may impair the via bility of cells that suffered DNA damage. Indeed a large number of studies have demonstrated that inhibition of PARP activity or knocking out/silencing PARP 1 may sensitize cells to the cytotoxic effects of ionizing radiation or DNA damaging agents such as DNA alkylators, cisplatin and topoisomerase poisons (De Vos et al., 2012) (see also Curtin and Szabó, 2013). A suc cessful series of clinical trials proved the feasibility of the use of PARP inhibitors as adjuvant chemotherapeutic agents for the treatment of cancer. Moreover, PARP inhibition may also work in monotherapy if tumor cells are defective in "backup" DNA repair mechanism (homologous recombination). This type of synthetic lethality is the basis for PARP inhibitor monotherapy of BRCA 1/2 deficient breast or ovarian cancers (see also Curtin and Szabó, 2013). Homologous recombination defects are not restricted to BRCA mutations but the "BRCA deficiency like" phenotype they cause may also sensitize cells to PARP inhibi tion: e.g. one in four sporadic breast cancers may be deficient in homologous recombination repair and thus be amenable for PARP inhibitor monotherapy.

\subsubsection{Cytotoxic role}

While PARylation may promote cell survival via assisting repair of DNA breaks, it may also be the mediator of cell death under certain conditions. An important challenge of PARylation research is to understand this dual role of PARPs and PARG in the regulation of cell death. Most cell biologists associate PARP 1 with apoptosis as in the 1990s this enzyme has become known as the first identified "death substrate" of caspases, the central executioners of apoptosis (Lazebnik et al., 1994). In addition to this passive role of PARP 1 , its active role in cell death appears to be more complex and more challenging to understand. As early as in 1983 Nathan Berger reported that cells treated with high levels of DNA damaging agents exhib ited $\mathrm{NAD}^{+}$and ATP depletion and a "marked impairment in their ability to conduct energy dependent functions" (Berger et al., 1983). The use of PARP inhibitors prevented the depletion of NAD ${ }^{+}$and ATP and partially restored the cells' ability to carry out DNA, RNA, and protein synthesis. The existence of the PARP mediated cytotoxic pathway has later been dem onstrated by many laboratories in a diverse set of cell death models. Later Virág et al. (Virág et al., 1998a, 1998b) and others have shown that the mode of DNA damage induced cell death mediated by PARP 1 is necrosis as supported by the morphol ogy of the cells and by permeabilization of the plasma membrane. PARP inhibitors or the PARP 1 knockout phenotype sup pressed necrosis and increased apoptosis, suggesting that PARP 1 acts as a molecular switch between apoptotic and necrotic cell death subroutines. An important observation was the discovery that PAR may leave the nucleus and trigger the release of apoptosis inducing factor (AIF) from mitochondria, thus mediating caspase independent cell death termed parthanatos (Andrabi et al., 2006; Wang et al., 2011; Yu et al., 2002, 2006). In contrast to its name, AIF is now increasingly recognized as a necrotic rather than an apoptotic mediator (Boujrad et al., 2007) providing further support for the necrotic role of PARylation.

An important question is what determines whether PARP 1 acts as a survival or a cytotoxic factor? It was proposed, and may be true for most cellular models of DNA damage induced cell death, that the severity of DNA damage is a key factor, with mild insults triggering apoptosis and severe ones inducing necrosis (Virág and Szabo, 2002). Moreover, stimulus and cell type dependent differences have also been found to determine the role of PARylation in cell death (Virág and Szabo, 2002) (see also Virág et al., 2013). Nonetheless, some questions regarding the exact mechanism of PARylation dependent cell death remain unanswered, including the following ones: (a) Is parthanatos the only PAR dependent cell death mechanism? (b) If other, non AIF mediated death pathways are also triggered by PARylation, then what are the molecular determinants of death pathway selection? (c) What is the role of $\mathrm{NAD}^{+} / \mathrm{ATP}$ depletion and metabolic reprogramming in parthanatos? (d) What is the activator of PAR synthesis in non DNA damage induced cell death? These and further questions will keep PARylation scientists busy for the years to come.

\subsection{Similar rather than antagonistic roles of PAR synthesis and PAR degradation}

For decades, PARylation research has been dominated by studies on PAR synthesis by PARP 1 whereas investigation of PAR degradation was largely neglected. Although PARG was discovered 40 years ago (Miwa and Sugimura, 1971; Ueda et al., 1972), its low abundance, high sensitivity to degradation and lack of specific and cell permeable inhibitors rendered the research on this enzyme rather difficult. According to our current knowledge, PARG exists in multiple isoforms resulting from alternative splicing and alternative translation initiation (Min and Wang, 2009). Only the full length (111 kDa) isoform localizes to the nucleus, whereas the others localize to the cytoplasm or the mitochondria. The PARG isoforms, however, may relocate under stress conditions (Haince et al., 2006). Interestingly, whereas PARP 1 deficient mice are viable and fertile, 
knocking out all PARG isoforms proved embryonic lethal (Koh et al., 2004). Our current understanding of the biological roles of PARG is mostly based on gene silencing studies and from data obtained from mice, in which only full length (111 kDa) PARG was missing.

Similar to protein kinases and phosphatases adding and removing phosphate groups to proteins for regulation, PARPs and PARG also represent two "antagonistic" sides of poly(ADP ribose) metabolism and were thus expected to exert opposite bio logical effects. In the kinase phosphatase paradigm several studies report opposing biological effects for kinase phosphatase pairs. For example, MAP kinase phosphatase 2 rescues cells from c jun $\mathrm{N}$ terminal kinase mediated apoptosis, induced by genotoxic stress (Cadalbert et al., 2005). Moreover, the protein phosphatase PTP1B suppressed transcriptional activation in duced by p210 bcr abl, the protein tyrosine kinase responsible for the initial manifestations of chronic myelogenous leuke mia (LaMontagne et al., 1998).

By analogy, PARPs and PARG may also be assumed to mediate biological phenomena in opposite direction. In contrast, however, it appears that in most cellular models studied so far, PARP 1 and PARG act in concert, rather than opposing each other's effects. Gene silencing studies have revealed that both PARP 1 and PARG are required for efficient DNA repair (Erdelyi et al., 2009; Fisher et al., 2007; Keil et al., 2006), as it could be shown that knockdown of either PARP 1 or PARG sensitizes cells to apoptotic cell death following DNA damage. Moreover, necrotic death triggered by severe genotoxic stimuli could be inhibited either by silencing PARP 1 or PARG (Erdelyi et al., 2009). Furthermore, synthetic lethality between homologous recombination defects and either PARP 1 or PARG knockdown has also been reported (Fathers et al., 2012). These data sup port a model in which both PAR synthesis and degradation are necessary for efficient repair of DNA breaks and for cell sur vival. Data obtained from PARG111 ${ }^{\prime}$ cells also recapitulated several previous findings of PARP 1 inhibition/knockout studies: defects in DNA repair, genomic instability (sister chromatid exchange, micronuclei) chromosomal aberrations (aneuploidy, chromosomal fragments/breaks and fusion) (Min et al., 2010). PARG111 knockout mice are hypersensitive to ionizing radiation and alkylating agents (Cortes et al., 2004) just like PARP 1 ' mice.

Similarly to cell death regulation, expression of hundreds of genes were found to be coordinately regulated by PARP 1 and PARG with both enzymes co localizing to target promoters and acting in a similar, rather than antagonistic manner to con tribute to the regulation of global expression patterns (Frizzell et al., 2009). Comparison of in vivo data obtained from exper iments with PARG111 / mice are slightly more controversial. Whereas PARP deficiency/inhibition provides protection from all oxidative stress related pathologies such as different forms of inflammation, diabetes, diabetic complications (vasculop athy, neuropathy, retinopathy), ischemia reperfusion injuries of the heart, brain, kidney and splanchnic areas (Virág and Szabo, 2002), PARG111 / mice were more susceptible to streptozotocin induced diabetes, endotoxin shock (Cortes et al., 2004) and postischemic brain damage (Cozzi et al., 2006). However, these mice were protected from renal ischemia reper fusion injury (Patel et al., 2005) and from splanchnic artery occlusion and reperfusion (Cuzzocrea et al., 2005). These data may indicate that the role played by PARylation in various in vivo conditions may not be explained by a uniform mechanism and may suggest model specific pathways differentially regulated by PARP 1 and PARG or PAR synthesis and degradation. Whereas in the case of PARP 1, inhibitor studies and gene knockout studies demonstrated similar biological effects, in the case of PARG it may be too early to compare the effects of PARG inhibition with PARG knockout. On the one hand PARG inhib itors have not yet been extensively characterized in terms of specificity and off target effects, while on the other hand the embryonic lethality of PARG knockout animals also precludes such comparisons. Thus it is not clear at the moment, which biological effects of PARG are mediated by its enzymatic effects and which are not. (Of note, PARP 1 has been shown to medi ate certain effects such as NF $\kappa B$ co activation via protein protein interaction without the need of enzymatic activity (Hassa et al., 2001)) In the light of the above, it may be important to decipher how to model the often similar and sometimes oppos ing effects of PARP 1 and PARG.

Some of these controversies may be resolved with the help of the kinase phosphatase analogy (Fig. 2). In scenario 1, mod ifying target proteins by the attachment of phosphate group/PAR polymer switches the function of the substrate on or off, whereas removal of the phosphate/PAR tag by a phosphatase/PARG may reverse the biological effect. In this case the kinase/ phosphatase or PARP/PARG pairs may mediate opposite responses. In scenario 2, kinases and PARP 1 can also automodify themselves leading to propagation of a signaling cascade or auto inhibition of the kinase or PARP 1. (Note: such inhibitory autophosphorylation has been reported for several kinase phosphatase pairs such as casein kinase + many Ser/Thr specific phosphatases, jun $\mathrm{N}$ terminal kinase + MAP kinase phosphatase 2, cyclin B cyclin dependent kinase $+\mathrm{cdc} 25 \mathrm{C}$ phosphatase, src kinases + CD45 phosphatase (Cadalbert et al., 2005; Gietzen and Virshup, 1999; Plas and Thomas, 1998; Sebastian et al., 1993).) For PARP 1, auto PARylation is thought to result in auto inhibition, which does not necessarily mean inhibition of enzyme activity as it may simply result in detachment of PARP 1 from the activating DNA break. Third, unlike for kinases and phosphatases, in the case of PARPs and PARG, the biological role of the cleaved tag (PAR polymers, oligomers or ADP ribose) should also be considered. Thus some effects of PARG inhibition/knockdown/knockout may be attributed to inhibi tion of free PAR signaling.

\subsection{PARylation and mitochondria}

One of the most intriguing issues in PARylation research is its role in the functional interplay between the nucleus and mitochondria. The controversial nature of this connection is best exemplified by the current situation where the presence of PAR degrading enzymes and activities in the mitochondria appears to be well established but the presence and/or activity 


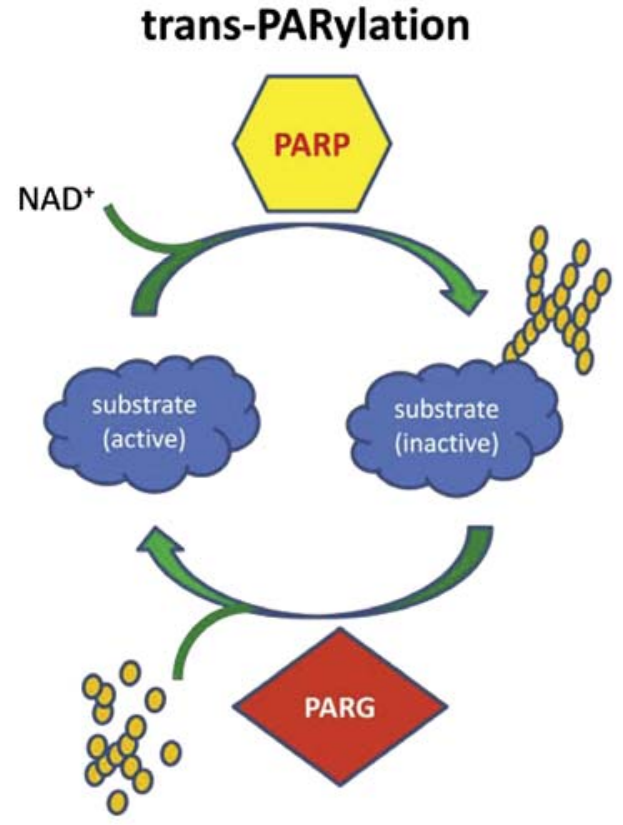

(ADP-ribose) $)_{n}$

\section{phosphorylation-dephosphorylation}

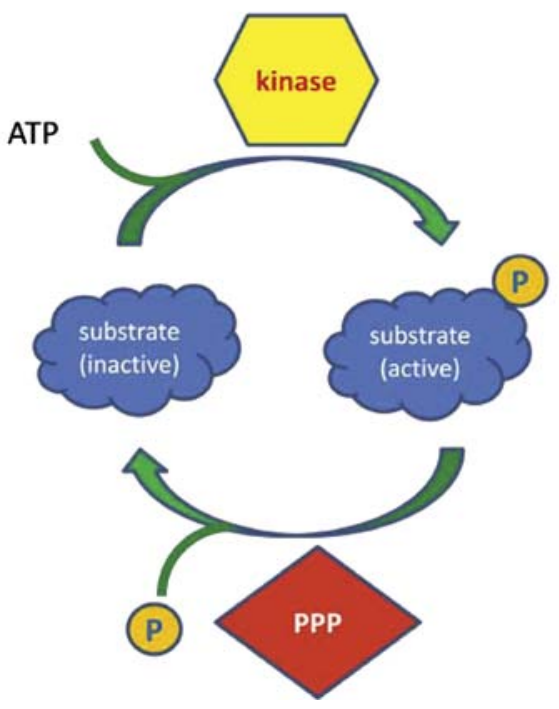

auto-PARylation

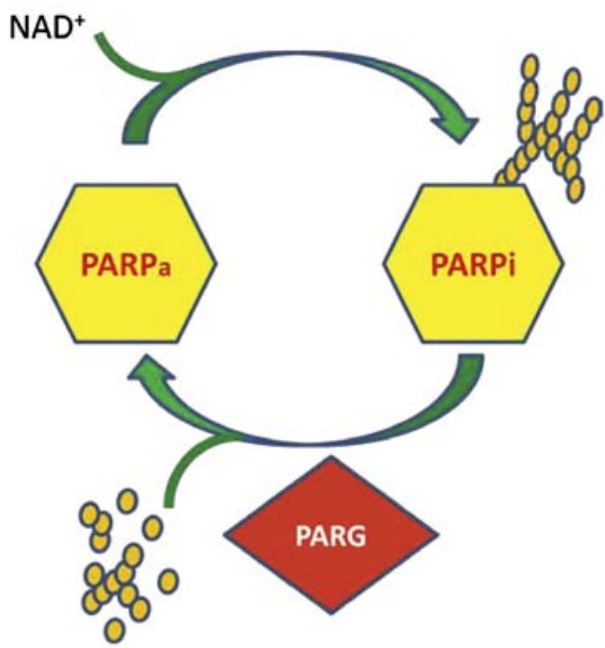

(ADP-ribose) $)_{n}$

Fig. 2. Analogy of PARylation/dePARylation by PARP/PARG to the operation of protein kinase/phosphatase pairs. Modifying target proteins by the attachment of phosphate group/PAR polymer switches the function of the substrate on or off, whereas removal of the phosphate/PAR tag by a phosphatase/ PARG may reverse the biological effect. In this case the kinase/phosphatase or PARP/PARG pairs may mediate opposite responses (transPARylation). Alternatively, kinases and PARP-1 can also automodify themselves leading to propagation of a signaling cascade or auto-inhibition of the kinase or PARP-1 (auto-PARylation).

of mitochondrial PAR synthesizing enzymes is debated and remains elusive. Here we present some recent developments around this controversial area of PARylation research and draw attention to some facets that require further elucidation.

\subsubsection{PAR synthesis in mitochondria?}

One of the enigmas to be solved in the field is PAR synthesis in the mitochondria. Is PAR synthesized in the mitochondria? What is the identity of mitochondrial PAR synthetase? Is the polymer synthesized in the organelle or does it simply trans locate from other sites of PAR synthesis? If PAR synthesis takes place in mitochondria, what is its biological role? This long list of fundamental open questions indicates that we are far from even a superficial understanding of whether and how and why PAR is made and functions in the mitochondria. 
Several attempts have been made to prove mitochondrial localization of PARP 1, with conflicting results (Table 1.). As early as in 1987 Masmoudi et al. (Masmoudi et al., 1988; Masmoudi and Mandel, 1987) purified mitochondrial DNA protein complexes, and an ADP ribosyltransferase (PARP) activity was found to be associated with the purified rat liver mitochon drial DNA protein complex. Predominant PAR acceptor proteins were also described and were found to range between 116 and $30 \mathrm{kDa}$. Later, immunoelectronmicroscopic investigation found a weak but clear PARP 1 signal in the mitochondria of Sertoli and HeLa cells (Mosgoeller et al., 1996). Moreover, in the brain of rats that suffered traumatic brain injury, both PARP 1 and PAR could be detected by dual label immunoelectronmicroscopy (Lai et al., 2008). This latter study also identi fied potential substrates (components of mitochondrial complexes III, IV and V) that were PARylated. Probably the most de tailed study addressing the issue of mitochondrial PARylation was published by Du et al. (2003). In this paper, mitochondrial PARP 1 protein and PARP activity could be detected in the mitochondrial fractions of fibroblasts. In neurons, the pattern of PARylated proteins showed a distinct and not overlapping pattern between mitochondria and nucleus. Whereas the only PARylated protein in the nucleus was above $120 \mathrm{kDa}$ (likely corresponding to automodified PARP 1), in the mitochondria several smaller $(<40 \mathrm{kDa})$ proteins were positive for PAR. Interestingly, the PARP inhibitor INH2BP inhibited mitochondrial but not nuclear PAR formation adding further layers of complexity to the puzzle to be assembled.

Other studies, however, found PARP 1 to be exclusively localized to the nucleus (Lapucci et al., 2011; Poitras et al., 2007). PARP 1 has also been reported to contribute to the repair of mitochondrial DNA damage (Druzhyna et al., 2000; Jarrett and Boulton, 2007) possibly indicating its mitochondrial occurrence. An alternative explanation has also been put forward to ex plain the effect of PARylation on mitochondrial DNA repair: Lapucci et al. (2011) have reported that inhibition or knockdown of PARP 1 reduced the integrity of mitochondrial genome and suppressed the expression of nuclear genes coding for mtDNA repair factors or mitochondrial transcription factors. These findings may explain mitochondrial effects of PARylation without the need for mitochondrial localization of the enzyme. A novel solution has also been suggested to explain the controversy between lack of mitochondrial PARP 1 and mitochondrial PARylation. Pankotai et al. (2009) identified alpha ketoglutarate dehydrogenase and especially one of its subunits dihydrolipoamide dehydrogenase as proteins with PARP like activity. In this study isolated mitochondria treated with hydrogen peroxide or a nitric oxide donor compound displayed PARylation activity and several PARylated mitochondrial proteins have also been identified. Although this study awaits conformation by other laboratories, it may open new avenues of research on non canonical PARP enzymes.

\subsubsection{PAR degradation in mitochondria}

Regardless of the way it may be formed, if PAR appears in the mitochondria we can rest assured that it will be degraded. Several lines of evidence suggest mitochondrial localization of PAR degrading enzymes PARG and ARH3 and PAR degrading activity has also been demonstrated.

The first surprising findings regarding the subcellular localization of PARG were published by Meyer Ficca et al. (2004) and Winstall et al. (1999) demonstrating that despite of the nuclear localization of the main PAR synthesizing enzymes PARP 1 and PARP 2, the majority of PARG showed perinuclear and cytoplasmic localization. Later Haince et al. (2006) pre sented data showing that PARG is mobile and can easily shuttle between the cytoplasm and the nucleus. The fraction that showed cytoplasmic localization has been later refined to be partially mitochondrial: Meyer et al. (2007) identified two small PARG isoforms (PARG55 and PARG60 corresponding to the mouse proteins mPARG63 and mPARG58, respectively) that were targeted to the mitochondria. In addition to the small mitochondrial isoform, Niere et al. (2008) also reported mitochondrial localization of the other PAR degrading enzyme ARH3. Interestingly, a follow up study from the same group (Niere et al., 2012) demonstrated that ARH3 and not the small PARG isoform is responsible for the degradation of mitochondrial ma trix associated PAR. These findings leave many questions open: what is the biological significance of ARH3 mediated PAR degradation in the mitochondria? What is the function of mitochondrial matrix associated PARG? Do mitochondrial and cytoplasmic PAR degrading enzymes shuttle between mitochondria and cytoplasm in response to nuclear or mitochondrial DNA damage? Further research is needed to clarify these issues.

\subsubsection{PAR signaling to mitochondria}

The first demonstration that PARP 1 activity dramatically impacts on mitochondrial function and structure was published by Virág et al. (1998a). They showed that in oxidatively stressed cells PARP 1 activation causes severe mitochondrial dys function as demonstrated by mitochondrial membrane depolarization, overproduction of superoxide and loss of cardiolipin content. Moreover, electron microscopic images revealed extensive destruction of mitochondrial ultrastructure (Fig. 3) fur ther reinforcing the functional link between PARylation by PARP 1 and mitochondria. The exact nature of this connection, however, still remains to be elusive. The above mentioned discovery by Dawson's group demonstrating that PAR released from the mitochondria induces the mitochondrial release and nuclear translocation of AIF provided an example that a PARP dependent nuclear mitochondrial crosstalk exists and mediates cell death following genotoxic stress. Later, upstream events triggering PARP 1 mediated mitochondrial dysfunction and downstream mediators have also been identified: RIP1 and TRAF mediated signaling was found to be responsible for PARP 1 mediated necrotic cell death and JNK was identified as a downstream mediator (Xu et al., 2006) (for more details see Section 3.4.2). In the mitochondria, respiratory complex I was shown to be the Achilles heel of mitochondrial electron transport chain which is most sensitive to the consequences of PARP activation, at least in a myocardial reperfusion injury model (Zhou et al., 2006). Some observations suggested that PARP 1 may be involved in the repair of mitochondrial DNA damage (Druzhyna et al., 2000; Jarrett and Boulton, 2007). How ever, these observations do not necessarily require PARP 1 to localize to the mitochondria as PARP 1 was identified as a 
Table 1

PARylation in mitochondria. Literature data regarding mitochondrial PAR synthesis, mitochondrial PAR degradation and mitochondrial PAR signaling are summarized.

\begin{tabular}{|c|c|c|}
\hline Experimental model & Findings & Reference \\
\hline \multicolumn{3}{|l|}{ PARP or PARylated proteins in mitochondria } \\
\hline Rat liver mitochondria & $\begin{array}{l}\text { ADP-ribosyl transferase and NAD glycohydrolase activities in } \\
\text { rat liver mitochondria. ART activity was not inhibited by 3- } \\
\text { aminobenzamide or nicotinamide }\end{array}$ & Masmoudi and Mandel (1987) \\
\hline Rat liver mitochondria & $\begin{array}{l}\text { The ADP-ribosyl transferase activity appears to be associated } \\
\text { with purified rat liver mitochondrial DNA protein complex. } \\
\text { Predominant acceptor proteins ranged between } 116-30 \mathrm{KDa}\end{array}$ & Masmoudi et al. (1993) \\
\hline $\begin{array}{l}\text { Human Sertoli cells and HeLa, immuno-electron } \\
\text { microscopy }\end{array}$ & $\begin{array}{l}\text { PARP immunoreactivity in mitochondria is higher than in the } \\
\text { cytoplasm }\end{array}$ & Mosgoeller et al. (1996) \\
\hline $\begin{array}{l}\text { Primary rat cortical neuron enriched cultures } \\
\text { fibroblasts from PARP-1/ and wild type mice }\end{array}$ & $\begin{array}{l}\text { detection of PARP-1 protein and PARP activity in } \\
\text { mitochondrial fractions }\end{array}$ & Du et al. (2003) \\
\hline Traumatic brain injury (TBI); & $\begin{array}{l}\text { PAR and PARP-1 were detected by dual label immuno- } \\
\text { electron microscopy in mitochondria after TBI } \\
\text { MALDI MS analysis identified components of mitochondrial } \\
\text { complexes III, IV and V as targets for PARylation } \\
\text { the PARP inhibitor INH2BP prevented peroxynitrite-induced } \\
\text { inhibition of respiration (oxygen consumption) in isolated } \\
\text { brain mitochondria }\end{array}$ & Lai et al. (2008) \\
\hline Isolated rat liver mitochondria & $\begin{array}{l}\text { treatment of mitochondria with hydrogen peroxide or the } \\
\text { nitric oxide donor GSNO induced PARylation of } \\
\text { mitochondrial proteins: mtALDH, ATPase, CPS1 and Otc } \\
\text { KGDH and DLDH (dihydrolipoamide dehydrogenase), a } \\
\text { subunit of both KGDH and PDH, was found to have PARP-like } \\
\text { activity }\end{array}$ & Pankotai et al. (2009) \\
\hline \multicolumn{3}{|l|}{ PAR degradation/PAR degrading enzymes in mitochondria } \\
\hline Embryonal fibroblasts from PARG111 / mice & $\begin{array}{l}\text { elevated PARG activity in the mitochondria isolated from } \\
\text { PARG111 / cells }\end{array}$ & Cortes et al. (2004) \\
\hline $\begin{array}{l}\text { HeLa, HEK293, MEFs from wild type and PARG111 ' } \\
\text { knockout mice }\end{array}$ & $\begin{array}{l}\text { small PARG isoforms (hPARG55, hPARG } 60 \text { and mPARG63 and } \\
\text { mPARG58) localize to mitochondria and mediate } \\
\text { mitochondrial PARG activity }\end{array}$ & Meyer et al. (2007) \\
\hline Primary rat neuronal cultures and rat brain sections & $\begin{array}{l}\text { PARG co-localizes with the mitochondrial proteins } \\
\text { cytochrome c and MnSOD } \\
\text { nuclear translocation of PARG is dependent on PARP-1 } \\
\text { activation }\end{array}$ & Poitras et al. (2007) \\
\hline $\begin{array}{l}\text { HEK293 cells stably transfected with mitochondrial } \\
\text { targeted PARP-1 }\end{array}$ & $\begin{array}{l}\text { PAR degrading activity in mitochondria } \\
\text { both ARH3 and PARG6i is present in mitochondria }\end{array}$ & Niere et al. (2008) \\
\hline HeLa & $\begin{array}{l}\text { endogenous and overexpressed PARG localizes to } \\
\text { mitochondria and can be detected in the mitochondrial } \\
\text { fraction after cell fractionation } \\
\text { mitochondrially enriched PARG is a small isoform ( } 55 \text { - } \\
60 \mathrm{kDa} \text { ) }\end{array}$ & Whatcott et al. (2009) \\
\hline $\begin{array}{l}\text { MEFs expressing mitoPARPcd } 1 \text { to artificially } \\
\text { produce PAR in mitochondria }\end{array}$ & $\begin{array}{l}\text { ARH3 but not PARG degrades PAR in mitochondria } \\
\text { human PARG } 55 \text { is the only mitochondrial PARG but it is } \\
\text { enzymatically inactive due to the absence of exon } 5 \text { encoded } \\
\text { amino acids }\end{array}$ & Niere et al. (2012) \\
\hline
\end{tabular}

PARylation signals to mitochondria

Primary murine thymocytes from PARP-1 / and wild type mice

RINr-38 pancreatic beta cell line treated with the alkylating agent methylnitrosourea (MNU)

MNNG-treated fibroblasts NMDA-treated neurons

isolated hearts from wild type and PARP-1 / mice

MEFs treated with the alkylating agent MNNG

Retinal pigment epithelial cells treated with $\mathrm{H}_{2} \mathrm{O}_{2}$ or the alkylating agent MMS hydrogen peroxide induces a PARP-1 dependent severe morphological deterioration in mitochondrial ultrastructure accompanied by mitochondrial dysfunction (mitochondrial membrane depolarization, superoxide production and loss of cardiolipin content)

PARP antisense inhibited the repair of MNU-induced Nmethylpurines in mitochondrial DNA

PAR-dependent translocation of AIF from mitochondria to the nucleus mediates cell death

ischemia reperfusion injury induces a PARP-1-mediated dysfunction of mitochondrial respiratory chain complex I

RIP1/TRAF signaling is required for PARP activation which causes mitochondrial dysfunction via JNK activation

the PARP inhibitor 3-aminobenzamide lowered mitochondrial DNA lesion repair capacity
Virag et al. (1998a)

Druzhyna et al. (2000)

Yu et al. (2002)

Zhou et al. (2006)

Xu et al. (2006)

Jarrett and Boulton (2007) 
Table 1 (continued)

\begin{tabular}{lll}
\hline Experimental model & Findings & Reference \\
\hline HeLa cells treated with MNNG & $\begin{array}{l}\text { ADP-ribose generated by PARG is further decomposed by } \\
\text { NUDT5 (ADP-sugar pyrophosphatase) and NUDT9 } \\
\text { mitochondrial ADP-ribose pyrophosphatase to yield AMP } \\
\text { that inhibits ADP/ATP translocator resulting in mitochondrial } \\
\text { energy failure }\end{array}$ \\
$\begin{array}{ll}\text { SHSY5Y human neuroblastoma cells and HeLa cells } \\
\text { treated with PARP-1 siRNA and PARP }\end{array}$ & $\begin{array}{l}\text { PARP inhibition or knockdown reduces integrity of } \\
\text { mitochondrial }\end{array}$ & Lapucci et al. (2011)
\end{tabular}

Abbreviations: ATPase $\mathrm{H}^{+}$, transporting two-sector ATP-ase, beta chain, mitochondrial; GSNO, S-nitrosoglutathione; KGDH, ketoglutarate dehydrogenase; MEF, mouse embryonal fibroblast; MMS, methylmethanesulfonate; MnSOD, manganese superoxide dismutase; RIP1, receptor-interacting protein 1; MNU, methyl-nitroso-urea; mtALDH, mitochondrial aldehyde dehydrogenase; OTC, ornithine transcarbamylase; PDH, pyruvate dehydrogenase; DLDH, dihydrolipoamide dehydrogenase; CPS1, carbamoyl phosphate synthetase 1.

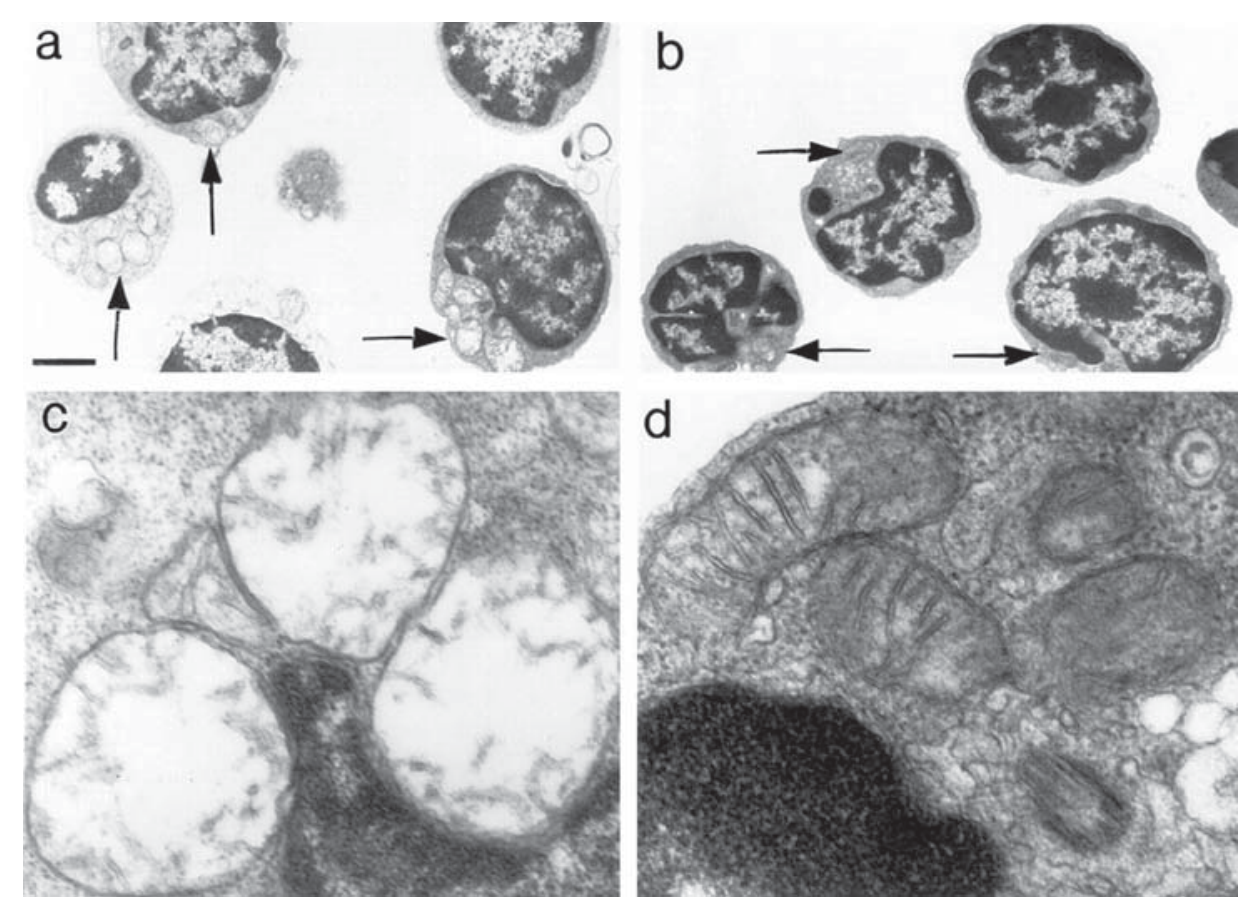

Fig. 3. PARP-1 mediates oxidative-stress-induced mitochondrial destruction. Thymocytes from wild type (a, c) and PARP-1 knockout mice (b, d) were treated with $20 \mu \mathrm{M}$ peroxynitrite for $3 \mathrm{~h}$ and then processed for electron microscopy. Hypodense cells with mitochondrial swelling, disrupted cristae indicate necrosis-associated mitochondrial injury. Magnification for $a, b, c$, and $d, 6640 \times, 6640 \times, 33 \times, 200 \times$, and $58,100 \times$, respectively. Scale bar $=2.5 \mu \mathrm{m}$ for $a$ and $b, 0.5 \mu \mathrm{m}$ for $c$, and $0.26 \mu \mathrm{m}$ for $d$. (Reproduced from Virág et al. J. Immunology 1998, Copyright 1998, The American Association of Immunologists, Inc, permission for reproduction granted by AAI.).

transcriptional regulator of nuclear genes encoding for mitochondrial repair factors and mitochondrial transcription factors (Lapucci et al., 2011). PAR degradation may also influence mitochondrial functions. An interesting study by Formentini et al. (2009) suggested that ADP ribose generated by PARG may be further catabolized by NUDIX enzymes (NUDT5 and NUDT9) functioning as mitochondrial ADP sugar/ribose pyrophosphatases. According to this scenario, AMP generated by these en zymes inhibits the ADP/ATP translocator resulting in mitochondrial energy failure.

An interesting question is whether signaling also occurs in the opposite direction (from mitochondria to the nucleus). The PARP dependent nuclear translocation of AIF is one nice example for mitochondria to nucleus signaling. Furthermore Kun et al. reported that PARP 1 may function as a sensor of ATP generated by oxidative phosphorylation and identified adenylate kinase as a cellular "wire" channeling ATP to the nucleus where it can inhibit PARP 1 (Kun et al., 2008). Of note ATP has pre viously been shown to inhibit PARP 1 with a $K_{\mathrm{i}}$ value corresponding to cellular ATP content $(3 \mathrm{mM})$ indicating a physiological relevance of this observation (Kun et al., 2004).

\subsection{Crosstalk between PARylation and signaling cascades}

Adaptation of cells to the ever changing environment is regulated by signal transduction pathways. Common elements of these pathways are receptors (cell surface or nuclear receptors), second messengers such as calcium or cyclic nucleotides and 
various kinases acting in concert with phosphatases. The way PARP 1 and PARG are integrated into these pathways is a rel atively new and very interesting branch of PARylation research which is expected to expand in the future. The facts that sup port the existence of a crosstalk between PARylation and signaling pathways are presented below.

\subsubsection{PARylation and calcium signaling}

Calcium signaling is a universal signaling mechanism both in excitable and non excitable cells. In a model of oxidative stress induced cytotoxicity, Virág et al. (1999) have demonstrated that a calcium signal was required for the activation of PARP 1. Pretreatment of cells with cell permeable calcium chelators blocked peroxynitrite induced PARP activation and con sequent cell death in primary murine thymocytes (Virág et al., 1999). These findings were later confirmed in other cell types (HaCaT keratinocytes, MEFs) and other oxidative stress signals (hydrogen peroxide, superoxide (Bakondi et al., 2003; Blenn et al., 2011)). Interestingly, in the same model, PARP 1 was also found to act upstream of a late, sustained elevation of cyto solic calcium "signal" indicating that not only calcium signaling activates PARP 1 but PARP 1 also regulates calcium redis tribution following intense oxidative stress (Virág et al., 1998a). Confirming these findings in a similar model of hydrogen peroxide induced cytotoxicity, Blenn et al. (2011) also identified TRPM2 as the step where PARP 1 and PARG regulate the flow of calcium from the extracellular compartment into the cytoplasm. The role of PARG is to generate ADP ribose that serves as the signal for TRPM2 activation and downstream events in oxidant induced cell death. A similar functional synergy between PARP and PARG has previously been published to account for the inhibition of ABC transporters in UVB treated cells (Dumitriu et al., 2004). These data identify (ADP ribose) ${ }_{n}$ as a new second messenger.

Homburg et al. (2000) provided evidence that a functional connection between calcium signal and PARP activation is not only relevant in cell death but also in the context of neuronal activation. This seminal paper placed PARP 1 into the signaling pathway mediated by PI3 kinase and calcium. Neurons depolarized by $\mathrm{KCl}$ treatment or electric stimulation showed a cal cium signal and a calcium dependent PARP activation in the absence of DNA breaks. Moreover, IP3 or thapsigargin added to nuclei isolated from unstimulated neurons to mobilize calcium from intracellular stores were also capable of inducing PARP activation indicating the key role of intracellular calcium mobilization in the activation of PARP 1 . Although calcium and magnesium may directly impact on PARP activity (Kun et al., 2004), the effect of calcium on PARP activation may also involve downstream signaling events such as calcium calmodulin dependent kinases. Indeed CamKII $\delta$ has been shown to activate PARP 1 by phosphorylation (Ju et al., 2004), a mechanism that appears to be more common than we previously thought (also see 3.4.2).

\subsubsection{PARylation in kinase cascades}

As discussed under Section 3.2, reversible PARylation by the concerted actions of PARPs and PARG is highly analogous to the operation of protein kinases and phosphatases. But there is more than just analogy between these two fields. Several lines of evidence (summarized in Table 2) suggest that (1) PARP 1 is regulated by phosphorylation and the effects of PARP 1 converge on or at least modulate downstream kinases. The first connection between kinases and PARP 1 linked PKC with PARP 1. In this early study by Tanaka et al. (1987) PARP 1 was shown to be a substrate for PKC which was later demonstrated by Bauer et al. (1992) to inhibit DNA binding and activation of PARP 1. The PKC activating phorbol esters were also found to cause PARP phosphorylation and to protect cells in a model of PARP activation dependent cell death (Hegedus et al., 2008) indicating that these observations may also have importance in a cellular setting. Many other kinases intimately linked to the DNA damage response such as DNA PK, ATM and ATR kinases have also been shown to interact with PARP 1. DNA PK can phosphorylate PARP 1 and PARP 1 can also activate or inhibit ATM and ATR kinases. (Binding of the negatively charged PAR polymer to ATM was suggested to be responsible for the inhibitory effect of PARP activation on the kinase.) Of note, many other kinases mediating DNA repair (CDK5, MAPK12, PLK3, PNKP, STK22c and STK36) have also been shown to be synthetic lethal in combination with PARP inhibition indicating that the repair pathway they are involved in is distinct from and complementary to the one mediated by PARylation (Turner et al., 2008). This latter situation does not imply direct inter action between the kinases and PARP 1 .

Kinase PARP interactions have also been implicated in biological phenomena distinct from DNA damage repair. For example CamKII $\delta$ has been shown to activate PARP 1 by phosphorylation which is a crucial event in the transcriptional reg ulation of neurogenic differentiation (Ju et al., 2004). Moreover, ILK (McPhee et al., 2008) and Txk kinases (Maruyama et al., 2007) phosphorylate PARP 1 to regulate the transcription of E cadherin and IFN $\gamma$, respectively. Furthermore, kinase PARP interactions have been shown to underlie regulations of additional cellular processes such as cell death (RIP kinase, JNK, Erk, p38, Akt) and FGF induced neuronal differentiation of embryonal stem cells (Erk) (see Table 2 for references). However, the exact molecular mechanism of the kinase PARP crosstalk in these and other conditions is not always known. Further systematic investigations such as the one by Gagne et al. (2009) combining in vitro kinase assays with mapping and verifi cation of phosphorylation sites and with cell based systems to verify biological relevance are clearly needed to advance our knowledge on the biological role of PARP phosphorylation. This is especially important as some data in the literature indi cates that PARP enzymatic activity absolutely requires the enzyme to be phosphorylated. For example PARP isolated from cells has been reported to be endogenously phosphorylated and removal of the phosphate groups by phosphatase treatment resulted in loss of enzyme activity (Gagne et al., 2009). Moreover, in Xenopus levis oocytes and eggs an equal amount of PARP protein could be detected but only eggs but not oocytes displayed PARP activity (Aoufouchi and Shall, 1997). When matu ration was induced in oocytes by progesterone treatment, it caused PARP phosphorylation (as indicated by a mobility shift of 


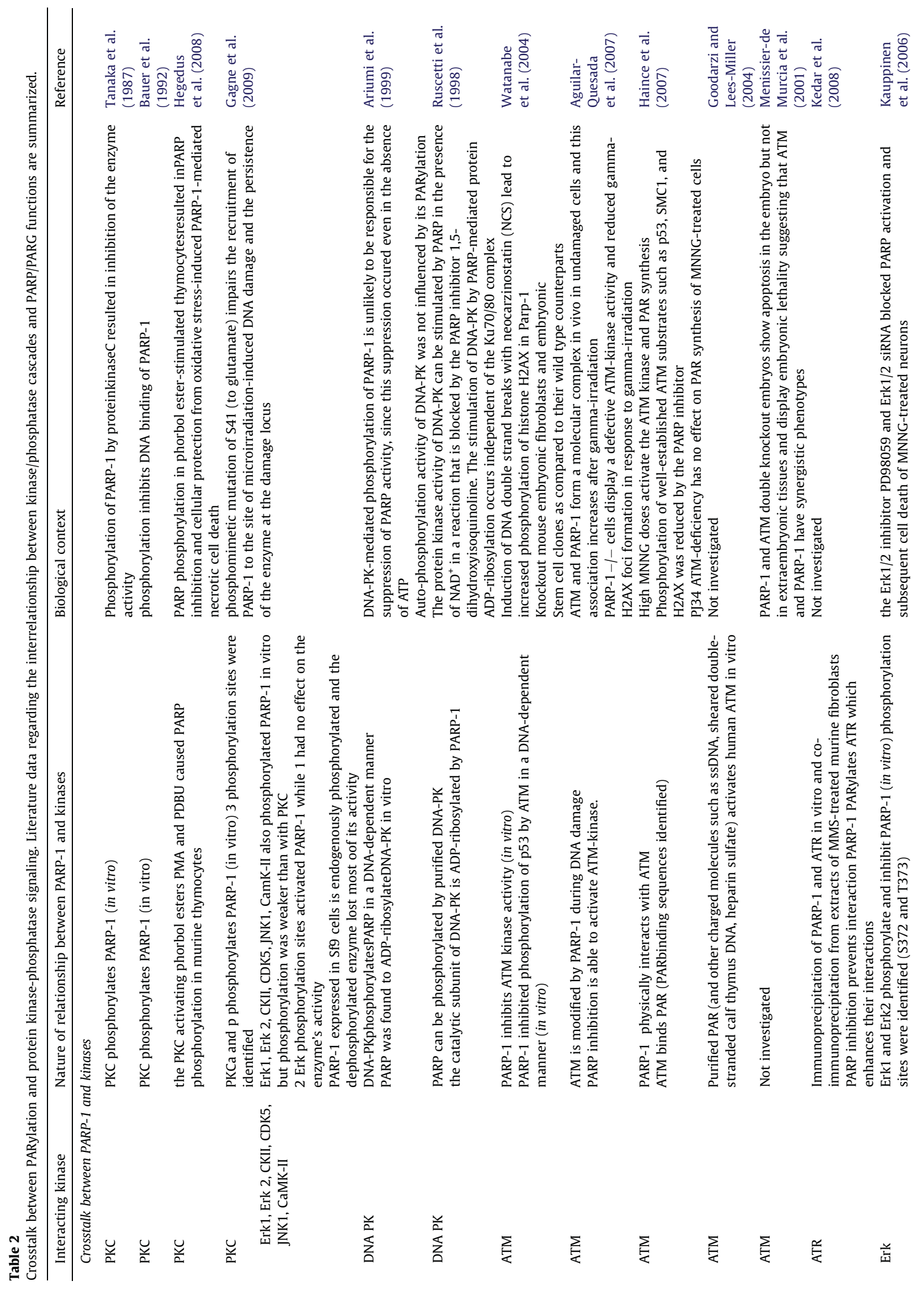


1059

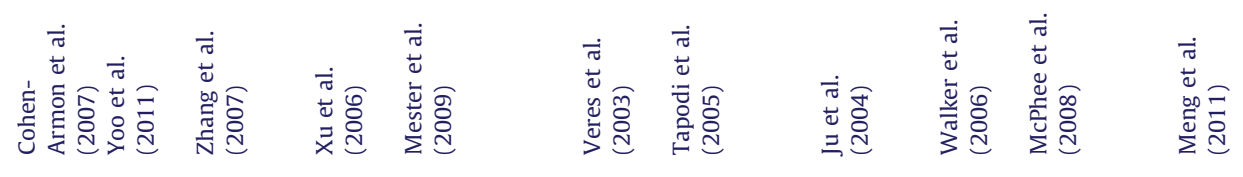

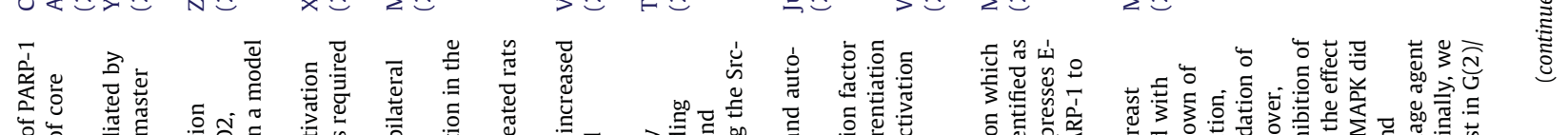

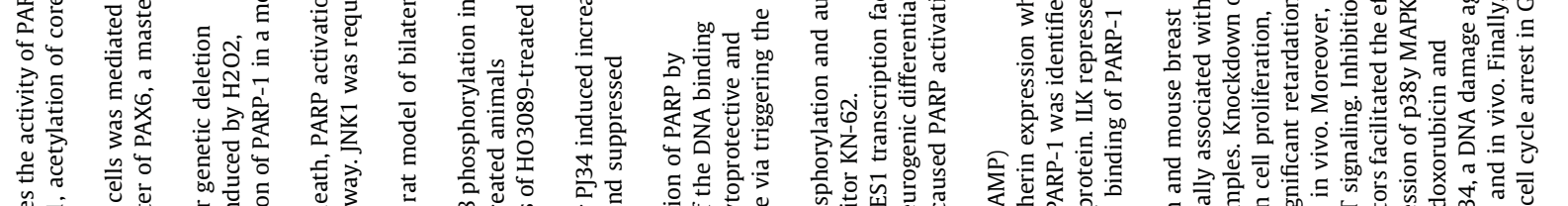

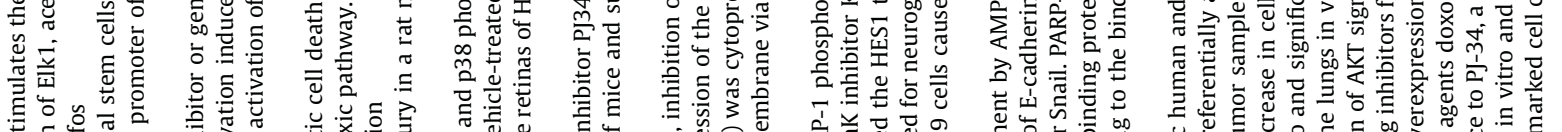

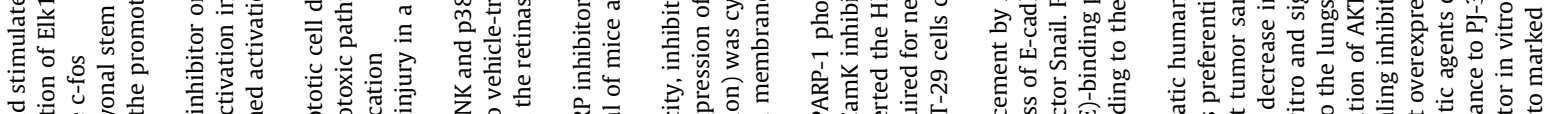

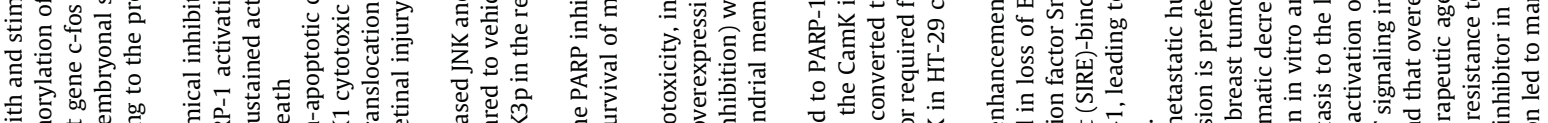

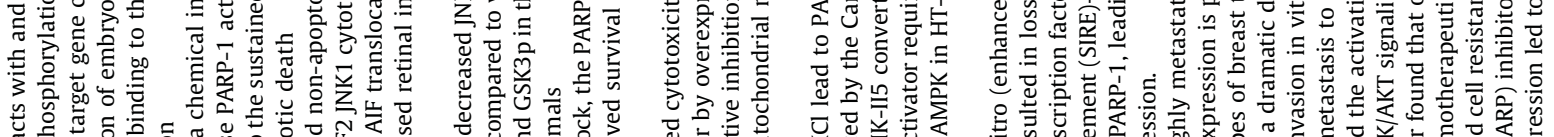

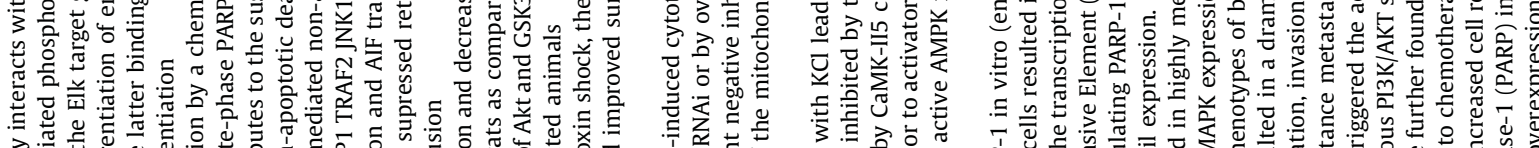

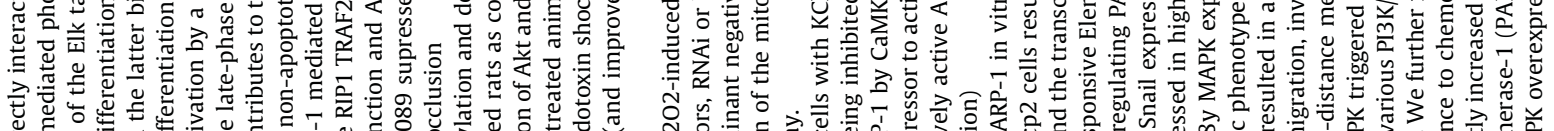

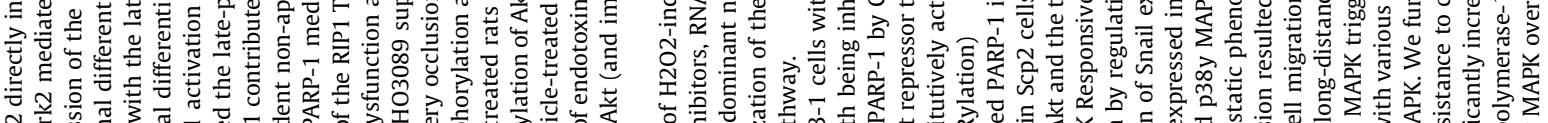

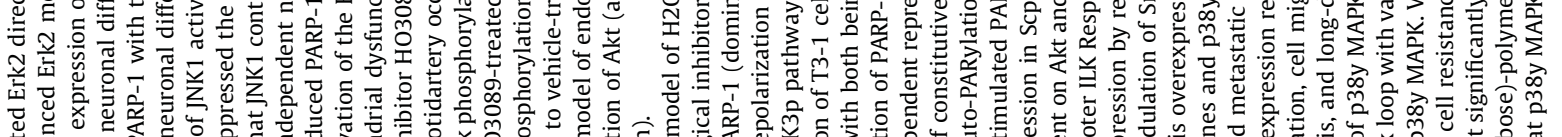

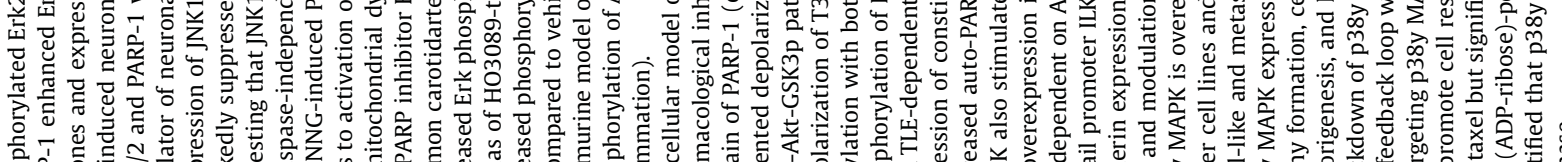

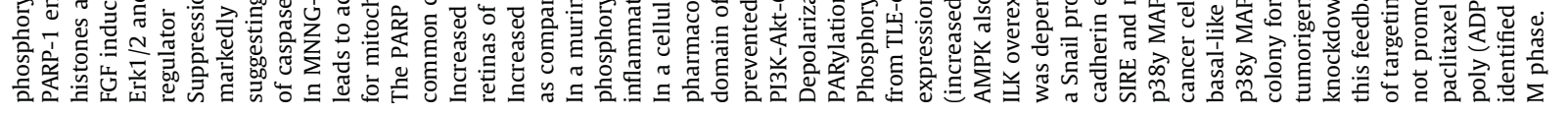

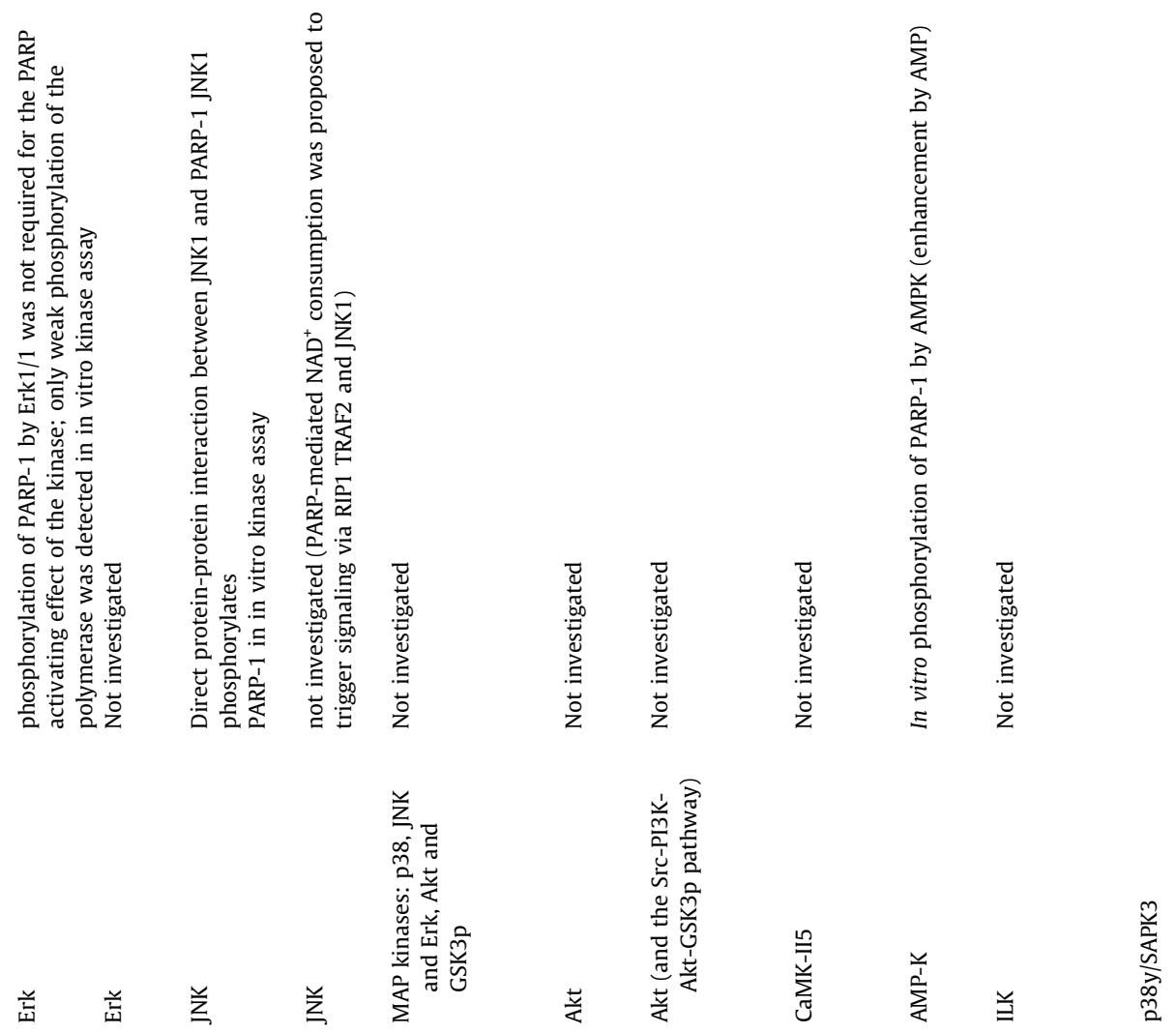




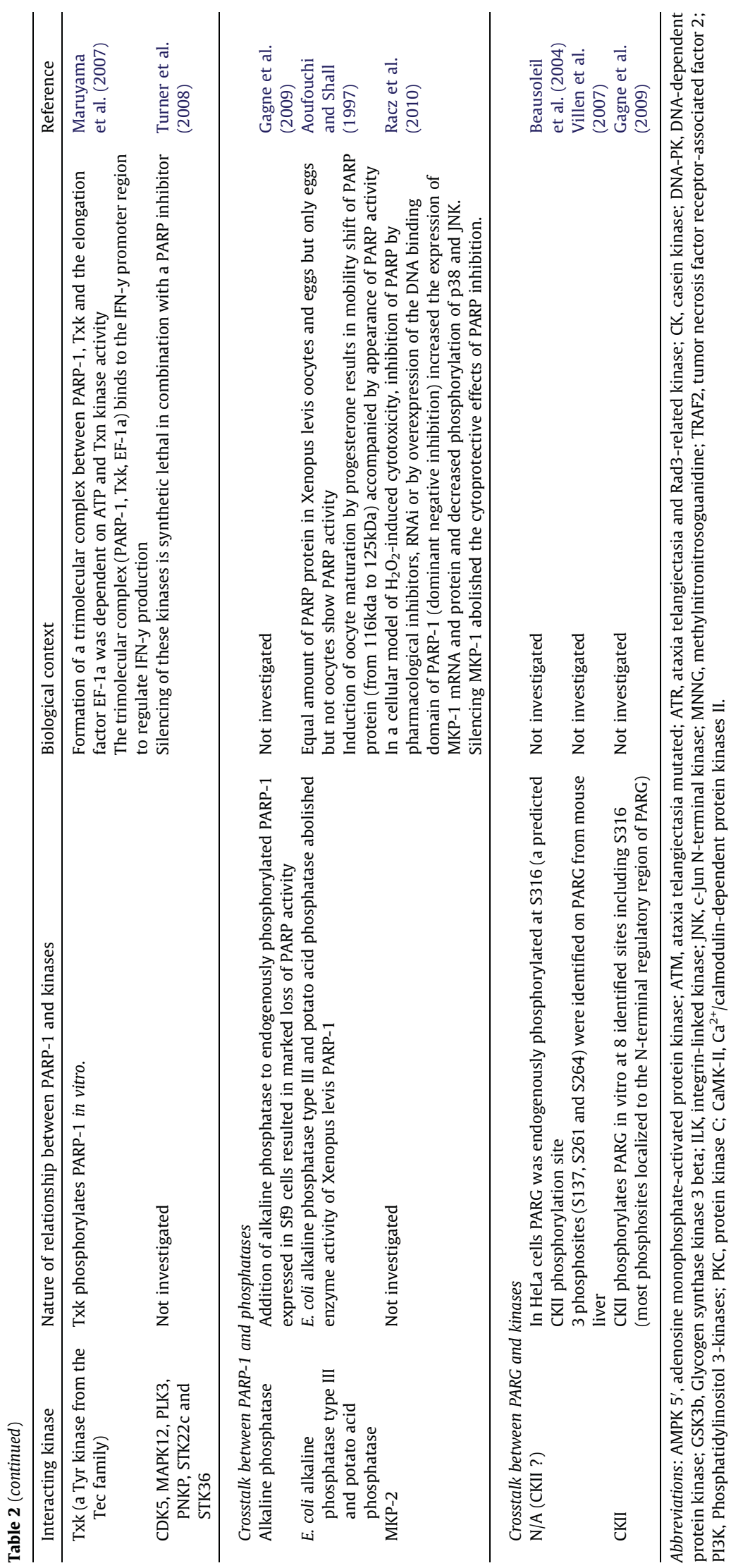


PARP protein from $116 \mathrm{kDa}$ to $125 \mathrm{kDa}$ ) and appearance of PARP activity (Aoufouchi and Shall, 1997). These data emphasize the crucial role of PTM in the regulation of PARP activity.

On the other side of the coin, phosphorylation cascades can also be modulated by PARylation either directly or indirectly. Several examples demonstrate (Table 2) that PARP1 can PARylate certain kinases or binding of the kinase to the PAR polymer affects the activity of the kinase. A rather unique way of regulating kinase cascades has also been demonstrated by Rácz et al., 2010. In a model of hydrogen peroxide induced cytotoxicity, they provided evidence for PARylation by PARP 1 serving as a repressor mechanism controlling the expression of the phosphatase MKP1 resulting in altered phosphorylation of the MAP kinases p38 and JNK. These interesting data highlight the so far neglected but very important role of protein phosphatases in mediating the cross talk between PARPs and kinase cascades.

\subsection{Divergent roles of PARP/PARylation in longevity and in age related disease}

Twenty years ago, Grube and Bürkle could show a positive correlation between poly(ADP ribose) polymerase activity in mononuclear leukocytes of 13 mammalian species with species specific life span (Grube and Burkle, 1992). Those data were perfectly compatible with a role of PARylation in genomic maintenance, as it appeared plausible that cells from long lived organisms should be equipped with more efficient maintenance mechanisms including DNA repair as compared to short lived ones (Kirkwood and Austad, 2000; Kirkwood and Holliday, 1979). Subsequently, enzymological comparison of recom binant human vs. rat PARP 1 provided an explanation for the difference in PARylation capacity between mammalian species of vastly differing life span (Beneke et al., 2000, 2010). Further support for a positive role of PARylation (by PARP 1) came from studies by Beneke and colleagues, revealing rapid positive regulation of telomere length via PARP 1 activity (Beneke et al., 2008).

Attempts at expressing the (more active) human PARP 1 in genetically modified mice led to more pronounced inflamma tory changes but not increased life span of the mice (Mangerich and Burkle, in press; Mangerich et al., 2009, 2010).

In contrast to the above scenario, PARP inhibition has a beneficial effect in several age related diseases such as ischemia reperfusion damage or Parkinson's disease (Koh et al., 2005; Virág and Szabo, 2002), which at first sight may seem paradox ical. One should, however, keep in mind that the evolutionary pressure towards maintenance of high levels of DNA mainte nance functions (such as DNA repair pathways, including PARylation) in order to guarantee a long life span can only be effective before the age of sexual maturity. Thereafter, individuals are in the "shadow of evolution" and gene functions that are beneficial in early life may turn into detrimental ones in later life ("antagonistic pleiotropy") (Kirkwood and Rose, 1991). In this context the PARylation system may be viewed as one example for antagonistic pleiotropy.

\section{New directions in PARylation research}

\subsection{Biological roles of PARP family members}

It goes without saying that the elucidation of the biological functions of the novel members of the PARP/ARTD family (Hottiger et al., 2010), especially ARTD4 through ARTD18, is of high priority. Significant progress has already been achieved, especially regarding ARTDs 4, 5, 6, 8, 9, 10 and 15, but overall our knowledge on these proteins is still rather limited. The importance of this aspect is also underpinned by the increasing use of PARylation inhibitors in clinical medicine for a variety of pathological conditions, raising the question of side effects arising from "collateral" inhibition of various members of the PARP/ARTD family.

\subsection{Structural biology of poly(ADP ribose) interactions}

While structural biology has already led to breakthroughs in PAR research (see above and in Karlberg et al., 2013), there is still a lot of scientific questions that call for further activity in this discipline. One example is the precise elucidation of the interaction of PAR with proteins carrying various PAR binding motifs and, even more complex, how a covalently PARylated protein may interact with PAR binding protein, or how several PAR binding molecules (of the same or of different nature) interact with the same ADP ribose chain.

With the increase in the amount of structural data on PARP family members an era of isoform specific inhibitors may soon be within reach. This desirable development would contribute to more successful and targeted translational applications in various diseases.

\section{Conflict of interest}

Authors declare no conflict of interest.

\section{Acknowledgements}

This work was supported by the following grants awarded to LV: OTKA K75864, K73003, K82009, TÁMOP 4.2.1./B 09/1/ KONV 2010 0007, TÁMOP 4.2.2.A 11/1/KONV 2012 0025, the National Innovation Office of Hungary (Baross program Sea 
horse grant, TeT 092010 0023); and by the following grants awarded to AB: DFG Collaborative Research Center 969/Project B04; DFG Research Training Group 1331/Project C4.

\section{References}

Aguilar-Quesada, R., Munoz-Gamez, J.A., Martin-Oliva, D., Peralta, A., Valenzuela, M.T., Matinez-Romero, R., Quiles-Perez, R., Menissier-de Murcia, J., de Murcia, G., Ruiz de Almodovar, M., Oliver, F.J., 2007. Interaction between ATM and PARP-1 in response to DNA damage and sensitization of ATM deficient cells through PARP inhibition. BMC Mol. Biol. 8, 29.

Ahel, I., Ahel, D., Matsusaka, T., Clark, A.J., Pines, J., Boulton, S.J., West, S.C., 2008. Poly(ADP-ribose)-binding zinc finger motifs in DNA repair/checkpoint proteins. Nature 451 (7174), 81-85.

Andrabi, S.A., Kim, N.S., Yu, S.W., Wang, H., Koh, D.W., Sasaki, M., Klaus, J.A., Otsuka, T., Zhang, Z., Koehler, R.C., Hurn, P.D., Poirier, G.G., Dawson, V.L., Dawson, T.M., 2006. Poly(ADP-ribose) (PAR) polymer is a death signal. Proc. Natl. Acad. Sci. USA 103 (48), 18308-18313.

Aoufouchi, S., Shall, S., 1997. Regulation by phosphorylation of Xenopus laevis poly(ADP-ribose) polymerase enzyme activity during oocyte maturation. Biochem. J. 325 (Pt 2), 543-551.

Ariumi, Y., Masutani, M., Copeland, T.D., Mimori, T., Sugimura, T., Shimotohno, K., Ueda, K., Hatanaka, M., Noda, M., 1999. Suppression of the poly(ADPribose) polymerase activity by DNA-dependent protein kinase in vitro. Oncogene 18 (32), 4616-4625.

Bakondi, E., Gonczi, M., Szabo, E., Bai, P., Pacher, P., Gergely, P., Kovacs, L., Hunyadi, J., Szabo, C., Csernoch, L., Virág, L., 2003. Role of intracellular calcium mobilization and cell-density-dependent signaling in oxidative-stress-induced cytotoxicity in HaCaT keratinocytes. J. Invest. Dermatol. 121 (1), $88-95$.

Bauer, P.I., Farkas, G., Buday, L., Mikala, G., Meszaros, G., Kun, E., Farago, A., 1992. Inhibition of DNA binding by the phosphorylation of poly ADP-ribose polymerase protein catalysed by protein kinase C. Biochem. Biophys. Res. Commun. 187 (2), 730-736.

Beausoleil, S.A., Jedrychowski, M., Schwartz, D., Elias, J.E., Villen, J., Li, J., Cohn, M.A., Cantley, L.C., Gygi, S.P., 2004. Large-scale characterization of HeLa cell nuclear phosphoproteins. Proc. Natl. Acad. Sci. USA 101 (33), 12130-12135.

Beneke, S., Alvarez-Gonzalez, R., Burkle, A., 2000. Comparative characterisation of poly(ADP-ribose) polymerase-1 from two mammalian species with different life span. Exp. Gerontol. 35 (8), 989-1002.

Beneke, S., Cohausz, O., Malanga, M., Boukamp, P., Althaus, F., Burkle, A., 2008. Rapid regulation of telomere length is mediated by poly(ADP-ribose) polymerase-1. Nucleic Acids Res. 36 (19), 6309-6317.

Beneke, S., Scherr, A.L., Ponath, V., Popp, O., Burkle, A., 2010. Enzyme characteristics of recombinant poly(ADP-ribose) polymerases-1 of rat and human origin mirror the correlation between cellular poly(ADP-ribosyl)ation capacity and species-specific life span. Mech. Ageing Dev. 131 (5), $366-369$.

Berger, N.A., Sims, J.L., Catino, D.M., Berger, S.J., 1983. Poly(ADP-ribose) polymerase mediates the suicide response to massive DNA damage: studies in normal and DNA-repair defective cells. Princess Takamatsu Symp. 13, 219-226.

Blenn, C., Wyrsch, P., Bader, J., Bollhalder, M., Althaus, F.R., 2011. Poly(ADP-ribose)glycohydrolase is an upstream regulator of Ca2+ fluxes in oxidative cell death. Cell Mol. Life Sci. 68 (8), 1455-1466.

Boujrad, H., Gubkina, O., Robert, N., Krantic, S., Susin, S.A., 2007. AIF-mediated programmed necrosis: a highly regulated way to die. Cell Cycle 6 (21), 26122619.

Bürkle, A., 2006. Poly(ADP-Ribosyl)ation. Landes Bioscience, Georgetown, TX, USA

Cadalbert, L., Sloss, C.M., Cameron, P., Plevin, R., 2005. Conditional expression of MAP kinase phosphatase-2 protects against genotoxic stress-induced apoptosis by binding and selective dephosphorylation of nuclear activated c-jun N-terminal kinase. Cell. Signal. 17 (10), $1254-1264$.

Canto C., Sauve A.A. Bai P., 2013. Crosstalk between poly(ADP-ribose) polymerase and sirtuin enzymes. Mol. Asp. Med. 34 (6), 1168-1201.

Chambon, P., Weill, J.D., Mandel, P., 1963. Nicotinamide mononucleotide activation of new DNA-dependent polyadenylic acid synthesizing nuclear enzyme. Biochem. Biophys. Res. Commun. 11 (39-43), 39-43.

Cherney, B.W., McBride, O.W., Chen, D.F., Alkhatib, H., Bhatia, K., Hensley, P., Smulson, M.E., 1987. CDNA sequence, protein structure, and chromosomal location of the human gene for poly(ADP-ribose) polymerase. Proc. Natl. Acad. Sci. USA 84 (23), 8370-8374.

Cohen-Armon, M., 2007. PARP-1 activation in the ERK signaling pathway. Trends Pharmacol. Sci. 28 (11), 556-560.

Cohen-Armon, M., Visochek, L., Rozensal, D., Kalal, A., Geistrikh, I., Klein, R., Bendetz-Nezer, S., Yao, Z., Seger, R., 2007. DNA-independent PARP-1 activation by phosphorylated ERK2 increases Elk1 activity: a link to histone acetylation. Mol. Cell 25 (2), 297-308.

Cortes, U., Tong, W.M., Coyle, D.L., Meyer-Ficca, M.L., Meyer, R.G., Petrilli, V., Herceg, Z., Jacobson, E.L., Jacobson, M.K., Wang, Z.Q., 2004. Depletion of the 110kilodalton isoform of poly(ADP-ribose) glycohydrolase increases sensitivity to genotoxic and endotoxic stress in mice. Mol. Cell Biol. 24 (16), $7163-$ 7178.

Cozzi, A., Cipriani, G., Fossati, S., Faraco, G., Formentini, L., Min, W., Cortes, U., Wang, Z.Q., Moroni, F., Chiarugi, A., 2006. Poly(ADP-ribose) accumulation and enhancement of postischemic brain damage in 110-kDa poly(ADP-ribose) glycohydrolase null mice. J. Cereb. Blood Flow Metab. 26 (5), 684-695.

Curtin, N.J., Szabo, C., 2013. Therapeutic applications of PARP inhibitors: Anticancer therapy and beyond. Mol. Asp. Med. 34 (6), $1217-1256$.

Cuzzocrea, S., Di Paola, R., Mazzon, E., Cortes, U., Genovese, T., Muia, C., Li, W., Xu, W., Li, J.H., Zhang, J., Wang, Z.Q., 2005. PARG activity mediates intestinal injury induced by splanchnic artery occlusion and reperfusion. FASEB J. 19 (6), 558-566.

de Murcia, G., Shall, S., 2000. Poly (ADP-ribosylation) Reactions: From DNA Damage and Stress Signalling to Cell Death. Oxford University Press, Oxford, UK.

De Vos, M., Schreiber, V., Dantzer, F., 2012. The diverse roles and clinical relevance of PARPs in DNA damage repair: current state of the art. Biochem. Pharmacol. 84 (12), 137-146.

Druzhyna, N., Smulson, M.E., LeDoux, S.P., Wilson, G.L., 2000. Poly(ADP-ribose) polymerase facilitates the repair of N-methylpurines in mitochondrial DNA. Diabetes 49 (11), 1849-1855.

Du, L., Zhang, X., Han, Y.Y., Burke, N.A., Kochanek, P.M., Watkins, S.C., Graham, S.H., Carcillo, J.A., Szabo, C., Clark, R.S., 2003. Intra-mitochondrial poly(ADPribosylation) contributes to NAD ${ }^{+}$depletion and cell death induced by oxidative stress. J. Biol. Chem. 278 (20), 18426-18433.

Dumitriu, I.E., Voll, R.E., Kolowos, W., Gaipl, U.S., Heyder, P., Kalden, J.R., Herrmann, M., 2004. UV irradiation inhibits ABC transporters via generation of ADPribose by concerted action of poly(ADP-ribose) polymerase-1 and glycohydrolase. Cell Death. Differ. 11 (3), 314-320.

Durkacz, B.W., Omidiji, O., Gray, D.A., Shall, S., 1980. (ADP-ribose)n participates in DNA excision repair. Nature 283 (5747), $593-596$.

Erdelyi, K., Bai, P., Kovacs, I., Szabo, E., Mocsar, G., Kakuk, A., Szabo, C., Gergely, P., Virág, L., 2009. Dual role of poly(ADP-ribose) glycohydrolase in the regulation of cell death in oxidatively stressed A549 cells. FASEB J. 23 (10), 3553-3563.

Fahrer, J., Kranaster, R., Altmeyer, M., Marx, A., Burkle, A., 2007. Quantitative analysis of the binding affinity of poly(ADP-ribose) to specific binding proteins as a function of chain length. Nucleic Acids Res. 35 (21), e143.

Fahrer, J., Popp, O., Malanga, M., Beneke, S., Markovitz, D.M., Ferrando-May, E., Burkle, A., Kappes, F., 2010. High-affinity interaction of poly(ADP-ribose) and the human DEK oncoprotein depends upon chain length. Biochemistry 49 (33), 7119-7130.

Fathers, C., Drayton, R.M., Solovieva, S., Bryant, H.E., 2012. Inhibition of poly(ADP-ribose) glycohydrolase (PARG) specifically kills BRCA2-deficient tumor cells. Cell Cycle 11 (5), 990-997.

Fisher, A.E., Hochegger, H., Takeda, S., Caldecott, K.W., 2007. Poly(ADP-ribose) polymerase 1 accelerates single-strand break repair in concert with poly(ADPribose) glycohydrolase. Mol. Cell Biol. 27 (15), 5597-5605.

Formentini, L., Macchiarulo, A., Cipriani, G., Camaioni, E., Rapizzi, E., Pellicciari, R., Moroni, F., Chiarugi, A., 2009. Poly(ADP-ribose) catabolism triggers AMPdependent mitochondrial energy failure. J. Biol. Chem. 284 (26), 17668-17676.

Frizzell, K.M., Gamble, M.J., Berrocal, J.G., Zhang, T., Krishnakumar, R., Cen, Y., Sauve, A.A., Kraus, W.L., 2009. Global analysis of transcriptional regulation by poly(ADP-ribose) polymerase-1 and poly(ADP-ribose) glycohydrolase in MCF-7 human breast cancer cells. J. Biol. Chem. 284 (49), $33926-33938$. 
Gagne, J.P., Moreel, X., Gagne, P., Labelle, Y., Droit, A., Chevalier-Pare, M., Bourassa, S., McDonald, D., Hendzel, M.J., Prigent, C., Poirier, G.G., 2009. Proteomic investigation of phosphorylation sites in poly(ADP-ribose) polymerase-1 and poly(ADP-ribose) glycohydrolase. J. Proteome Res. 8 (2), $1014-1029$.

Gietzen, K.F., Virshup, D.M., 1999. Identification of inhibitory autophosphorylation sites in casein kinase I epsilon. J. Biol. Chem. 274 (45), 3206332070.

Goodarzi, A.A., Lees-Miller, S.P., 2004. Biochemical characterization of the ataxia-telangiectasia mutated (ATM) protein from human cells. DNA Repair (Amst) 3 (7), 753-767.

Grube, K., Burkle, A., 1992. Poly(ADP-ribose) polymerase activity in mononuclear leukocytes of 13 mammalian species correlates with species-specific life span. Proc. Natl. Acad. Sci. USA 89 (24), 11759-11763.

Haenni, S.S., Hassa, P.O., Altmeyer, M., Fey, M., Imhof, R., Hottiger, M.O., 2008. Identification of lysines 36 and 37 of PARP-2 as targets for acetylation and auto-ADP-ribosylation. Int. J. Biochem. Cell Biol. 40 (10), 2274-2283.

Haince, J.F., Kozlov, S., Dawson, V.L., Dawson, T.M., Hendzel, M.J., Lavin, M.F., Poirier, G.G., 2007. Ataxia telangiectasia mutated (ATM) signaling network is modulated by a novel poly(ADP-ribose)-dependent pathway in the early response to DNA-damaging agents. J. Biol. Chem. 282 (22), 16441-16453.

Haince, J.F., Ouellet, M.E., McDonald, D., Hendzel, M.J., Poirier, G.G., 2006. Dynamic relocation of poly(ADP-ribose) glycohydrolase isoforms during radiationinduced DNA damage. Biochim. Biophys. Acta 1763 (2), 226-237.

Hassa, P.O., Covic, M., Hasan, S., Imhof, R., Hottiger, M.O., 2001. The enzymatic and DNA binding activity of PARP-1 are not required for NF-kappa B coactivator function. J. Biol. Chem. 276 (49), 45588-45597.

Hassa, P.O., Haenni, S.S., Buerki, C., Meier, N.I., Lane, W.S., Owen, H., Gersbach, M., Imhof, R., Hottiger, M.O., 2005. Acetylation of poly(ADP-ribose) polymerase-1 by p300/CREB-binding protein regulates coactivation of NF-kappa B-dependent transcription. J. Biol. Chem. 280 (49), $40450-40464$.

Hegedus, C., Lakatos, P., Olah, G., Toth, B.I., Gergely, S., Szabo, E., Biro, T., Szabo, C., Virág, L., 2008. Protein kinase C protects from DNA damage-induced necrotic cell death by inhibiting poly(ADP-ribose) polymerase-1. FEBS Lett. 582 (12), 1672-1678.

Homburg, S., Visochek, L., Moran, N., Dantzer, F., Priel, E., Asculai, E., Schwartz, D., Rotter, V., Dekel, N., Cohen-Armon, M., 2000. A fast signal-induced activation of Poly(ADP-ribose) polymerase: a novel downstream target of phospholipase C. J. Cell Biol. 150 (2), $293-307$.

Hottiger, M.O., Hassa, P.O., Luscher, B., Schuler, H., Koch-Nolte, F., 2010. Toward a unified nomenclature for mammalian ADP-ribosyltransferases. Trends Biochem. Sci. 35 (4), 208-219.

Jarrett, S.G., Boulton, M.E., 2007. Poly(ADP-ribose) polymerase offers protection against oxidative and alkylation damage to the nuclear and mitochondrial genomes of the retinal pigment epithelium. Ophthalmic Res. 39 (4), 213-223.

Jeffery, C.J., 2003. Moonlighting proteins: old proteins learning new tricks. Trends Genet. 19 (8), 415-417.

Ju, B.G., Lunyak, V.V., Perissi, V., Garcia-Bassets, I., Rose, D.W., Glass, C.K., Rosenfeld, M.G., 2006. A topoisomerase IIbeta-mediated dsDNA break required for regulated transcription. Science 312 (5781), 1798-1802.

Ju, B.G., Solum, D., Song, E.J., Lee, K.J., Rose, D.W., Glass, C.K., Rosenfeld, M.G., 2004. Activating the PARP-1 sensor component of the groucho/TLE1 corepressor complex mediates a camkinase iidelta-dependent neurogenic gene activation pathway. Cell 119 (6), 815-829.

Juarez-Salinas, H., Sims, J.L., Jacobson, M.K., 1979. Poly(ADP-ribose) levels in carcinogen-treated cells. Nature 282 (5740), $740-741$.

Kappes, F., Fahrer, J., Khodadoust, M.S., Tabbert, A., Strasser, C., Mor-Vaknin, N., Moreno-Villanueva, M., Burkle, A., Markovitz, D.M., Ferrando-May, E., 2008. DEK is a poly(ADP-ribose) acceptor in apoptosis and mediates resistance to genotoxic stress. Mol. Cell Biol. 28 (10), $3245-3257$.

Karlberg, T., Hammarstrom, M., Schutz, P., Svensson, L., Schuler, H., 2010. Crystal structure of the catalytic domain of human PARP2 in complex with PARP inhibitor ABT-888. Biochemistry 49 (6), 1056-1058.

Karlberg T., Langelier M.F., Pascal J.M., Schüler H., 2013. Structural biology of the writers, readers, ane erasers in mono- and poly-ADP-ribose mediated signaling. Mol. Asp. Med. 34 (6), 1088-1108.

Kauppinen, T.M., Chan, W.Y., Suh, S.W., Wiggins, A.K., Huang, E.J., Swanson, R.A., 2006. Direct phosphorylation and regulation of poly(ADP-ribose) polymerase-1 by extracellular signal-regulated kinases 1/2. Proc. Natl. Acad. Sci. USA 103 (18), 7136-7141.

Kedar, P.S., Stefanick, D.F., Horton, J.K., Wilson, S.H., 2008. Interaction between PARP-1 and ATR in mouse fibroblasts is blocked by PARP inhibition. DNA Repair (Amst) 7 (11), 1787-1798.

Keil, C., Grobe, T., Oei, S.L., 2006. MNNG-induced cell death is controlled by interactions between PARP-1, poly(ADP-ribose) glycohydrolase, and XRCC1. J. Biol. Chem. 281 (45), 34394-34405.

Kim, M.Y., Mauro, S., Gevry, N., Lis, J.T., Kraus, W.L., 2004. NAD(+)-dependent modulation of chromatin structure and transcription by nucleosome binding properties of PARP-1. Cell 119 (6), 803-814.

Kirkwood, T.B., Austad, S.N., 2000. Why do we age? Nature 408 (6809), 233-238.

Kirkwood, T.B., Holliday, R., 1979. The evolution of ageing and longevity. Proc. R. Soc. Lond. B. Biol. Sci. 205 (1161), $531-546$.

Kirkwood, T.B., Rose, M.R., 1991. Evolution of senescence: late survival sacrificed for reproduction. Philos. Trans. R. Soc. Lond. B. Biol. Sci. 332 (1262), 15-24.

Koh, D.W., Dawson, T.M. Dawson, V.L. 2005. Mediation of cell death by poly(ADP-ribose) polymerase-1. Pharmacol. Res. 52 (1), 5-14.

Koh, D.W., Lawler, A.M., Poitras, M.F., Sasaki, M., Wattler, S., Nehls, M.C., Stoger, T., Poirier, G.G., Dawson, V.L., Dawson, T.M., 2004. Failure to degrade poly(ADP-ribose) causes increased sensitivity to cytotoxicity and early embryonic lethality. Proc. Natl. Acad. Sci. USA 101 (51), $17699-17704$.

Kraus, W.L., Hottiger, W.L., 2013. PARP-1 and gene regulation: Progress and puzzles. Mol. Asp. Med. 34 (6), 1109-1123.

Krenzlin, H., Demuth, I., Salewsky, B., Wessendorf, P., Weidele, K., Burkle, A., Digweed, M., 2012. DNA damage in Nijmegen Breakage Syndrome cells leads to PARP hyperactivation and increased oxidative stress. PLoS Genet. 8 (3), e1002557.

Krishnakumar, R., Gamble, M.J., Frizzell, K.M., Berrocal, J.G., Kininis, M., Kraus, W.L., 2008. Reciprocal binding of PARP-1 and histone H1 at promoters specifies transcriptional outcomes. Science 319 (5864), 819-821.

Kun, E., Kirsten, E., Hakam, A., Bauer, P.I., Mendeleyev, J., 2008. Identification of poly(ADP-ribose) polymerase-1 as the OXPHOS-generated ATP sensor of nuclei of animal cells. Biochem. Biophys. Res. Commun. 366 (2), 568-573.

Kun, E., Kirsten, E., Mendeleyev, J., Ordahl, C.P., 2004. Regulation of the enzymatic catalysis of poly(ADP-ribose) polymerase by dsDNA, polyamines, Mg(2+) $\mathrm{Ca}(2+)$, histones $\mathrm{H}(1)$ and $\mathrm{H}(3)$, and ATP. Biochemistry 43 (1), 210-216.

Kurosaki, T., Ushiro, H., Mitsuuchi, Y., Suzuki, S., Matsuda, M., Matsuda, Y., Katunuma, N., Kangawa, K., Matsuo, H., Hirose, T., 1987. Primary structure of human poly(ADP-ribose) synthetase as deduced from cDNA sequence. J. Biol. Chem. 262 (33), 15990-15997.

Lai, Y., Chen, Y., Watkins, S.C., Nathaniel, P.D., Guo, F., Kochanek, P.M., Jenkins, L.W., Szabo, C., Clark, R.S., 2008. Identification of poly-ADP-ribosylated mitochondrial proteins after traumatic brain injury. J. Neurochem. 104 (6), 1700-1711.

LaMontagne Jr., K.R., Flint, A.J., Franza Jr., B.R., Pandergast, A.M., Tonks, N.K., 1998. Protein tyrosine phosphatase 1B antagonizes signalling by oncoprotein tyrosine kinase p210 bcr-abl in vivo. Mol. Cell Biol. 18 (5), 2965-2975.

Langelier, M.F., Planck, J.L., Roy, S., Pascal, J.M., 2012. Structural basis for DNA damage-dependent poly(ADP-ribosyl)ation by human PARP-1. Science 336 (6082), 728-732.

Lapucci, A., Pittelli, M., Rapizzi, E., Felici, R., Moroni, F., Chiarugi, A., 2011. Poly(ADP-ribose) polymerase-1 is a nuclear epigenetic regulator of mitochondrial DNA repair and transcription. Mol. Pharmacol. 79 (6), 932-940.

Lazebnik, Y.A., Kaufmann, S.H., Desnoyers, S., Poirier, G.G., Earnshaw, W.C., 1994. Cleavage of poly(ADP-ribose) polymerase by a proteinase with properties like ICE. Nature 371 (6495), 346-347.

Lonskaya, I., Potaman, V.N., Shlyakhtenko, L.S., Oussatcheva, E.A., Lyubchenko, Y.L., Soldatenkov, V.A., 2005. Regulation of poly(ADP-ribose) polymerase-1 by DNA structure-specific binding. J. Biol. Chem. 280 (17), 17076-17083.

Loseva, O., Jemth, A.S., Bryant, H.E., Schuler, H., Lehtio, L., Karlberg, T., Helleday, T., 2010. PARP-3 is a mono-ADP-ribosylase that activates PARP-1 in the absence of DNA. J. Biol. Chem. 285 (11), 8054-8060.

Mangerich, A., Burkle, A., in press. Pleiotropic cellular functions of PARP1 in longevity and aging: genome maintenance meets inflammation. Oxid. Med. Cell Longev. 
Mangerich, A., Herbach, N., Hanf, B., Fischbach, A., Popp, O., Moreno-Villanueva, M., Bruns, O.T., Burkle, A., 2010. Inflammatory and age-related pathologies in mice with ectopic expression of human PARP-1. Mech. Ageing Dev. 131 (6), 389-404.

Mangerich, A., Scherthan, H., Diefenbach, J., Kloz, U., van der Hoeven, F., Beneke, S., Burkle, A., 2009. A caveat in mouse genetic engineering: ectopic gene targeting in ES cells by bidirectional extension of the homology arms of a gene replacement vector carrying human PARP-1. Transgenic Res. 18 (2), 261279.

Mao, Z., Hine, C., Tian, X., Van Meter, M., Au, M., Vaidya, A., Seluanov, A., Gorbunova, V., 2011. SIRT6 promotes DNA repair under stress by activating PARP1. Science 332 (6036), 1443-1446.

Maruyama, T., Nara, K., Yoshikawa, H., Suzuki, N., 2007. Txk, a member of the non-receptor tyrosine kinase of the Tec family, forms a complex with poly(ADP-ribose) polymerase 1 and elongation factor 1alpha and regulates interferon-gamma gene transcription in Th1 cells. Clin. Exp. Immunol. 147 (1), 164-175.

Masmoudi, A., el-Fetouaki, J., Weltin, D., Belhadj, O., Mandel, P., 1993. Association of mitochondrial ADP-ribosyl transferase activity with the DNA-protein complex. Biochem. Mol. Biol. Int. 29 (1), 77-83.

Masmoudi, A., Islam, F., Mandel, P., 1988. ADP-ribosylation of highly purified rat brain mitochondria. J. Neurochem. 51 (1), $188-193$.

Masmoudi, A., Mandel, P., 1987. ADP-ribosyl transferase and NAD glycohydrolase activities in rat liver mitochondria. Biochemistry 26 (7), $1965-1969$.

McPhee, T.R., McDonald, P.C., Oloumi, A., Dedhar, S., 2008. Integrin-linked kinase regulates E-cadherin expression through PARP-1. Dev. Dyn. 237 (10), $2737-2747$.

Meng, F., Zhang, H., Liu, G., Kreike, B., Chen, W., Sethi, S., Miller, F.R., Wu, G., 2011. P38gamma mitogen-activated protein kinase contributes to oncogenic properties maintenance and resistance to poly (ADP-ribose)-polymerase-1 inhibition in breast cancer. Neoplasia 13 (5), $472-482$.

Menissier-de Murcia, J., Mark, M., Wendling, O., Wynshaw-Boris, A., De Murcia, G., 2001. Early embryonic lethality in PARP-1 ATM double-mutant mice suggests a functional synergy in cell proliferation during development. Mol. Cell Biol. 21 (5), 1828-1832.

Mester, L., Szabo, A., Atlasz, T., Szabadfi, K., Reglodi, D., Kiss, P., Racz, B., Tamas, A., Gallyas Jr., F., Sumegi, B., Hocsak, E., Gabriel, R., Kovacs, K., 2009. Protection against chronic hypoperfusion-induced retinal neurodegeneration by PARP inhibition via activation of PI-3-kinase Akt pathway and suppression of JNK and p38 MAP kinases. Neurotox. Res. $16(1), 68-76$.

Meyer-Ficca, M.L., Meyer, R.G., Coyle, D.L., Jacobson, E.L., Jacobson, M.K., 2004. Human poly(ADP-ribose) glycohydrolase is expressed in alternative splice variants yielding isoforms that localize to different cell compartments. Exp. Cell Res. 297 (2), 521-532.

Meyer, R.G., Meyer-Ficca, M.L., Whatcott, C.J., Jacobson, E.L., Jacobson, M.K., 2007. Two small enzyme isoforms mediate mammalian mitochondrial poly(ADP-ribose) glycohydrolase (PARG) activity. Exp. Cell Res. 313 (13), 2920-2936.

Min, W., Cortes, U., Herceg, Z., Tong, W.M., Wang, Z.Q., 2010. Deletion of the nuclear isoform of poly(ADP-ribose) glycohydrolase (PARG) reveals its function in DNA repair, genomic stability and tumorigenesis. Carcinogenesis 31 (12), 2058-2065.

Min, W., Wang, Z.Q., 2009. Poly (ADP-ribose) glycohydrolase (PARG) and its therapeutic potential. Front. Biosci. 14, 1619-1626.

Miwa, M., Sugimura, T., 1971. Splitting of the ribose-ribose linkage of poly(adenosine diphosphate ribose) by a calf thymus extract. J. Biol. Chem. 246, 63626364.

Mosgoeller, W., Steiner, M., Hozak, P., Penner, E., Wesierska-Gadek, J., 1996. Nuclear architecture and ultrastructural distribution of poly(ADPribosyl)transferase, a multifunctional enzyme. J. Cell Sci. 109 (Pt 2), 409-418.

Niere, M., Kernstock, S., Koch-Nolte, F., Ziegler, M., 2008. Functional localization of two poly(ADP-ribose)-degrading enzymes to the mitochondrial matrix. Mol. Cell Biol. 28 (2), 814-824.

Niere, M., Mashimo, M., Agledal, L., Dolle, C., Kasamatsu, A., Kato, J., Moss, J., Ziegler, M., 2012. ADP-ribosylhydrolase 3 (ARH3), not poly(ADP-ribose) glycohydrolase (PARG) isoforms, is responsible for degradation of mitochondrial matrix-associated poly(ADP-ribose). J. Biol. Chem. 287 (20), 1608816102.

Nishizuka, Y., Ueda, K., Honjo, T., Hayaishi, O., 1968. Enzymic adenosine diphosphate ribosylation of histone and poly adenosine diphosphate ribose synthesis in rat liver nuclei. J. Biol. Chem. 243 (13), 3765-3767.

Nishizuka, Y., Ueda, K., Nakazawa, K., Hayaishi, O., 1967. Studies on the polymer of adenosine diphosphate ribose. I. Enzymic formation from nicotinamide adenine dinuclotide in mammalian nuclei. J. Biol. Chem. 242 (13), 3164-3171.

Pankotai, E., Lacza, Z., Muranyi, M., Szabo, C., 2009. Intra-mitochondrial poly(ADP-ribosyl)ation: potential role for alpha-ketoglutarate dehydrogenase. Mitochondrion 9 (2), 159-164.

Panzeter, P.L., Realini, C.A., Althaus, F.R., 1992. Noncovalent interactions of poly(adenosine diphosphate ribose) with histones. Biochemistry 31 (5), 13791385.

Patel, N.S., Cortes, U., Di Poala, R., Mazzon, E., Mota-Filipe, H., Cuzzocrea, S., Wang, Z.Q., Thiemermann, C., 2005. Mice lacking the 110-kD isoform of poly(ADP-ribose) glycohydrolase are protected against renal ischemia/reperfusion injury. J. Am. Soc. Nephrol. 16 (3), $712-719$.

Plas, D.R., Thomas, M.L., 1998. Negative regulation of antigen receptor signaling in lymphocytes. J. Mol. Med. (Berl) 76 (8), $589-595$.

Pleschke, J.M., Kleczkowska, H.E., Strohm, M., Althaus, F.R., 2000. Poly(ADP-ribose) binds to specific domains in DNA damage checkpoint proteins. J. Biol. Chem. 275 (52), 40974-40980.

Poitras, M.F., Koh, D.W., Yu, S.W., Andrabi, S.A., Mandir, A.S., Poirier, G.G., Dawson, V.L., Dawson, T.M., 2007. Spatial and functional relationship between poly(ADP-ribose) polymerase-1 and poly(ADP-ribose) glycohydrolase in the brain. Neuroscience 148 (1), 198-211.

Popp, O., Veith, S., Fahrer, J., Bohr, V.A., Burkle, A., Mangerich, A., in press. Site-specific noncovalent interaction of the biopolymer poly(ADP-ribose) with the werner syndrome protein regulates protein functions. ACS Chem. Biol.

Racz, B., Hanto, K., Tapodi, A., Solti, I., Kalman, N., Jakus, P., Kovacs, K., Debreceni, B., Gallyas Jr., F., Sumegi, B., 2010. Regulation of MKP-1 expression and MAPK activation by PARP-1 in oxidative stress: a new mechanism for the cytoplasmic effect of PARP-1 activation. Free Radic. Biol. Med. 49 (12), 19781988.

Robert, I., Karicheva, O., Reina San Martin, B., Schreiber, V., Dantzer, F., 2013. Functional aspects of PARylation in induced and programmed DNA repair processes: Preserving genome integrity and modulating physiological events. Mol. Asp. Med. 34 (6), 1138-1152.

Ruf, A., Mennissier de Murcia, J., de Murcia, G., Schulz, G.E., 1996. Structure of the catalytic fragment of poly(AD-ribose) polymerase from chicken. Proc. Natl. Acad. Sci. USA 93 (15), 7481-7485.

Ruf, A., Rolli, V., De Murcia, G., Schulz, G.E., 1998. The mechanism of the elongation and branching reaction of poly(ADP-ribose) polymerase as derived from crystal structures and mutagenesis. J. Mol. Biol. 278 (1), 57-65.

Ruscetti, T., Lehnert, B.E., Halbrook, J., Le Trong, H., Hoekstra, M.F., Chen, D.J., Peterson, S.R., 1998. Stimulation of the DNA-dependent protein kinase by poly(ADP-ribose) polymerase. J. Biol. Chem. 273 (23), 14461-14467.

Sauermann, G., Wesierska-Gadek, J., 1986. Poly(ADP-ribose) effectively competes with DNA for histone H4 binding. Biochem. Biophys. Res. Commun. 139 (2), 523-529.

Sebastian, B., Kakizuka, A., Hunter, T., 1993. Cdc25M2 activation of cyclin-dependent kinases by dephosphorylation of threonine-14 and tyrosine-15. Proc. Natl. Acad. Sci. USA 90 (8), 3521-3524.

Shieh, W.M., Ame, J.C., Wilson, M.V., Wang, Z.Q., Koh, D.W., Jacobson, M.K., Jacobson, E.L., 1998. Poly(ADP-ribose) polymerase null mouse cells synthesize ADP-ribose polymers. J. Biol. Chem. 273 (46), 30069-30072.

Sugimura, T., Fujimura, S., Hasegawa, S., Kawamura, Y., 1967. Polymerization of the adenosine $5^{\prime}$-diphosphate ribose moiety of NAD by rat liver nuclear enzyme. Biochim. Biophys. Acta 138 (2), 438-441.

Suzuki, H., Uchida, K., Shima, H., Sato, T., Okamoto, T., Kimura, T., Miwa, M., 1987. Molecular cloning of cDNA for human poly(ADP-ribose) polymerase and expression of its gene during HL-60 cell differentiation. Biochem. Biophys. Res. Commun. 146 (2), 403-409.

Tanaka, Y., Koide, S.S., Yoshihara, K., Kamiya, T., 1987. Poly (ADP-ribose) synthetase is phosphorylated by protein kinase C in vitro. Biochem. Biophys. Res. Commun. 148 (2), 709-717. 
Tapodi, A., Debreceni, B., Hanto, K., Bognar, Z., Wittmann, I., Gallyas Jr., F., Varbiro, G., Sumegi, B., 2005. Pivotal role of Akt activation in mitochondrial protection and cell survival by poly(ADP-ribose)polymerase-1 inhibition in oxidative stress. J. Biol. Chem. 280 (42), 35767-35775.

Timinszky, G., Till, S., Hassa, P.O., Hothorn, M., Kustatscher, G., Nijmeijer, B., Colombelli, J., Altmeyer, M., Stelzer, E.H., Scheffzek, K., Hottiger, M.O., Ladurner, A.G., 2009. A macrodomain-containing histone rearranges chromatin upon sensing PARP1 activation. Nat. Struct. Mol. Biol. 16 (9), $923-929$.

Turner, N.C., Lord, C.J., Iorns, E., Brough, R., Swift, S., Elliott, R., Rayter, S., Tutt, A.N., Ashworth, A., 2008. A synthetic lethal siRNA screen identifying genes mediating sensitivity to a PARP inhibitor. EMBO J. 27 (9), 1368-1377.

Ueda, K., Oka, J., Naruniya, S., Miyakawa, N., Hayaishi, O., 1972. Poly ADP-ribose glycohydrolase from rat liver nuclei, a novel enzyme degrading the polymer. Biochem. Biophys. Res. Commun. 46 (2), 516-523.

Veres, B., Gallyas Jr., F., Varbiro, G., Berente, Z., Osz, E., Szekeres, G., Szabo, C., Sumegi, B., 2003. Decrease of the inflammatory response and induction of the Akt/protein kinase B pathway by poly-(ADP-ribose) polymerase 1 inhibitor in endotoxin-induced septic shock. Biochem. Pharmacol. 65 (8), $1373-1382$.

Villen, J., Beausoleil, S.A., Gerber, S.A., Gygi, S.P., 2007. Large-scale phosphorylation analysis of mouse liver. Proc. Natl. Acad. Sci. USA 104 (5), 1488-1493.

Virág, L., Robaszkiewicz, A., Rodriguez-Vargas, J.M., Oliver, F.J., 2013. Poly(ADP-ribose) signaling in cell death. Mol. Asp. Med. 34 (6), $1153-1167$.

Virág, L., Salzman, A.L., Szabo, C., 1998a. Poly(ADP-ribose) synthetase activation mediates mitochondrial injury during oxidant-induced cell death. J. Immunol. 161 (7), 3753-3759.

Virág, L., Scott, G.S., Antal-Szalmas, P., O’Connor, M., Ohshima, H., Szabo, C., 1999. Requirement of intracellular calcium mobilization for peroxynitriteinduced poly(ADP-ribose) synthetase activation and cytotoxicity. Mol. Pharmacol. 56 (4), 824-833.

Virág, L., Scott, G.S., Cuzzocrea, S., Marmer, D., Salzman, A.L., Szabo, C., 1998b. Peroxynitrite-induced thymocyte apoptosis: the role of caspases and poly (ADP-ribose) synthetase (PARS) activation. Immunology 94 (3), 345-355.

Virág, L., Szabo, C., 2002. The therapeutic potential of poly(ADP-ribose) polymerase inhibitors. Pharmacol. Rev. 54 (3), $375-429$.

Walker, J.W., Jijon, H.B., Madsen, K.L., 2006. AMP-activated protein kinase is a positive regulator of poly(ADP-ribose) polymerase. Biochem. Biophys. Res. Commun. 342 (1), 336-341.

Wang, Y., Kim, N.S., Haince, J.F., Kang, H.C., David, K.K., Andrabi, S.A., Poirier, G.G., Dawson, V.L., Dawson, T.M., 2011. Poly(ADP-ribose) (PAR) binding to apoptosis-inducing factor is critical for PAR polymerase-1-dependent cell death (parthanatos). Sci. Signal. 4 (167), ra20.

Watanabe, F., Fukazawa, H., Masutani, M., Suzuki, H., Teraoka, H., Mizutani, S., Uehara, Y., 2004. Poly(ADP-ribose) polymerase-1 inhibits ATM kinase activity in DNA damage response. Biochem. Biophys. Res. Commun. 319 (2), 596-602.

Weidele, K., Kunzmann, A., Schmitz, M., Beneke, S., Burkle, A., 2010. Ex vivo supplementation with nicotinic acid enhances cellular poly(ADP-ribosyl)ation and improves cell viability in human peripheral blood mononuclear cells. Biochem. Pharmacol. 80 (7), 1103-1112.

Whatcott, C.J., Meyer-Ficca, M.L., Meyer, R.G., Jacobson, M.K., 2009. A specific isoform of poly(ADP-ribose) glycohydrolase is targeted to the mitochondrial matrix by a N-terminal mitochondrial targeting sequence. Exp. Cell Res. 315 (20), 3477-3485.

Winstall, E., Affar, E.B., Shah, R., Bourassa, S., Scovassi, I.A., Poirier, G.G., 1999. Preferential perinuclear localization of poly(ADP-ribose) glycohydrolase. Exp. Cell Res. 251 (2), 372-378.

Xu, Y., Huang, S., Liu, Z.G., Han, J., 2006. Poly(ADP-ribose) polymerase-1 signaling to mitochondria in necrotic cell death requires RIP1/TRAF2-mediated JNK1 activation. J. Biol. Chem. 281 (13), 8788-8795.

Yoo, Y.D., Huang, C.T., Zhang, X., Lavaute, T.M., Zhang, S.C., 2011. Fibroblast growth factor regulates human neuroectoderm specification through ERK1/2PARP-1 pathway. Stem Cells 29 (12), 1975-1982.

Yu, S.W., Andrabi, S.A., Wang, H., Kim, N.S., Poirier, G.G., Dawson, T.M., Dawson, V.L., 2006. Apoptosis-inducing factor mediates poly(ADP-ribose) (PAR) polymer-induced cell death. Proc. Natl. Acad. Sci. USA 103 (48), 18314-18319.

Yu, S.W., Wang, H., Poitras, M.F., Coombs, C., Bowers, W.J., Federoff, H.J., Poirier, G.G., Dawson, T.M., Dawson, V.L., 2002. Mediation of poly(ADP-ribose) polymerase-1-dependent cell death by apoptosis-inducing factor. Science 297 (5579), 259-263.

Zhang, S., Lin, Y., Kim, Y.S., Hande, M.P., Liu, Z.G., Shen, H.M., 2007. C-Jun N-terminal kinase mediates hydrogen peroxide-induced cell death via sustained poly(ADP-ribose) polymerase-1 activation. Cell Death Differ. 14 (5), 1001-1010.

Zhou, H.Z., Swanson, R.A., Simonis, U., Ma, X., Cecchini, G., Gray, M.O., 2006. Poly(ADP-ribose) polymerase-1 hyperactivation and impairment of mitochondrial respiratory chain complex I function in reperfused mouse hearts. Am. J. Physiol. Heart Circ. Physiol. 291 (2), H714-H723. 